\title{
基于程函方程的远震成像方法反演青藏高原 东北缘速度和径向各向异性结构
}

\author{
李孟洋 ${ }^{1,2}$, 刘少林 ${ }^{1 *}$, 杨顶辉 ${ }^{3}$, 徐锡伟 ${ }^{1}$, 申文豪 ${ }^{1}$, 解朝娣 ${ }^{2}$, 汪文帅 ${ }^{4}$, 杨树新 ${ }^{1}$
}

1. 应急管理部国家自然灾害防治研究院, 北京 100085 ;

2. 云南大学地球科学学院, 昆明 650091 ;

3. 清华大学数学科学系, 北京 100084 ;

4. 宁夏大学数学计算机学院, 银川 750021

* 通讯作者, E-mail: shaolinliu88@163.com

收稿日期: 2021-06-21; 收修改稿日期: 2021-11-18; 接受日期: 2021-12-08; 网络版发表日期: 2022-02-07 应急管理部国家自然灾害防治研究院基本科研业务专项项目(编号: ZDJ2019-18)、地震科学联合基金项目(编号: U1839026)、国家自然科学 基金项目(批准号: 42174111、42064004)和中国地震局地球物理研究所基本科研业务费专项项目(编号: DQJB16A03、DQJB17A01)资助

摘要 青藏高原东北缘位于阿拉善地块、鄂尔多斯地块、昆仑一西秦岭地块、四川盆地与青藏高原的交汇处, 是 青藏块体向大陆内部扩展的前缘, 正经历着强烈的变形作用. 目前关于青藏高原东北缘的构造演化机制仍存在争 议, 通过研究青藏高原东北缘下方壳幔结构可以为青藏高原构造演化机制提供新约束. 文章收集了青藏高原东北 缘及周边地区921 个宽频地震台站从2006年8月至2020年10月记录的地震波形数据, 一共选取了667个远震事件, 获得了770749对直达P波互相关走时残差数据. 利用基于程函方程的远震层析成像方法, 获得了青藏高原东北缘 下方30 800 km的P波速度和径向各向异性结构模型. 结果显示, 祁连造山带、松潘-甘孜地块东北部和秦岭褶皱带 西部下地壳存在明显的低速异常和正径向各向异性, 表明这些区域下方中下地壳存在物质水平流动. 祁连造山 带、松潘-甘孜地块东北部和秦岭褶皱带西部上地幔顶部表现为明显的低速异常和正径向各向异性，表明这些区 域下方具有弱的岩石圈, 并且存在地幔流. 鄂尔多斯地块和四川盆地上地幔顶部均表现为高速异常和明显的负径 向各向异性，表明其下方岩石圈具有较强的力学强度. 川滇块体北部下方存在高速异常，可能代表了北向俯冲的 印度板块, 其俯冲前缘可能到达鲜水河断裂而并未俯冲至昆仑断裂.

关键词青藏高原东北缘, 层析成像, P波速度结构, 径向各向异性结构, 印度板块

\section{1 引言}

青藏高原的隆升源于印度板块和欧亚板块自 $\sim 55 \mathrm{Ma}$ 以来的持续碰撞(Zheng和Wu, 2018). 由于印度
板块的俯冲、板块间的强烈挤压作用以及青藏高原物 质运动, 在青藏高原内部形成众多火山, 如可可西里火 山、昆仑山火山群等，并且在关键构造区呈现高地表 热流值, 如印度-雅鲁藏布江缝合带 $\left(\sim 152 \mathrm{~mW} \mathrm{~m}^{-2}\right)$ 、

\footnotetext{
中文引用格式: 李孟洋, 刘少林, 杨顶辉, 徐锡伟, 申文豪, 解朝娣, 汪文帅, 杨树新. 2022. 基于程函方程的远震成像方法反演青藏高原东北缘速度和径向各向 异性结构. 中国科学: 地球科学, 52(5): 860-881, doi: 10.1360/SSTe-2021-0176

英文引用格式: Li M, Liu S, Yang D, Xu X, Shen W, Xie C, Wang W, Yang S. 2022. Velocity structure and radial anisotropy beneath the northeastern Tibetan Plateau revealed by eikonal equation-based teleseismic P-wave traveltime tomography. Science China Earth Sciences, 65(5): 824-844, https://oi.org/ $10.1007 / \mathrm{s} 11430-021-9876-\mathrm{y}$
} 
班公湖-怒江缝合带( 140 $\mathrm{mW} \mathrm{m}^{-2}$ )等(汪集旸和黄少 鹏, 1988; 姜光政等, 2016). 此外, 在青藏高原及周边发 育了一系列大型活动断裂，如龙门山断裂、鲜水河断 裂、小江断裂、红河断裂和昆仑断裂等(图1). 在这些 断裂上地震活动频繁，最近二十年先后发生了一系列 7.0 级以上地震, 如 2001 年 $M_{\mathrm{s}} 8.1$ 昆仑山口西地震、 2008 年 $M_{\mathrm{s}} 8.0$ 汶川地震、2010年 $M_{\mathrm{s}} 7.1$ 玉树地震、2013 年 $M_{\mathrm{s}} 7.0$ 芦山地震、2017年 $M_{\mathrm{s}} 7.0$ 九寨沟地震和 2021 年 $M_{\mathrm{s}} 7.4$ 青海玛多地震等. 青藏高原以其复杂且强烈的构 造活动现象吸引了研究者的广泛关注, 然而青藏高原 的构造演化特别是青藏高原的隆升和变形机制一直存 在争议. 针对这一问题，前人提出了构造逃逸模型 (Molnar和Tapponnier, 1975; Tapponnier等, 2001)、黏 性薄层模型(England和McKenzie，1982)和地壳流模型 (Clark和Royden, 2000)等. 然而, 目前青藏高原的隆升 与变形仍未形成统一认识(Liang等, 2012; Wu等, 2015; Lei和Zhao, 2016; Wu等, 2018; Zhang等, 2018; 滕吉文 等, 2019; Wu等, 2019). 为了探究青藏高原隆升变形机 制，本文选取青藏高原关键构造区一一青藏高原东北 缘, 研究青藏东北缘及周边地区壳幔结构, 将有助于 理解青藏高原隆升和变形机制.

青藏高原东北缘位于鄂尔多斯地块、昆仑-西秦 岭地块、四川盆地与青藏高原的交汇处，其内部发育 有阿尔金断裂、北祁连断裂、昆仑断裂和海原断裂等 多条大型断裂(图1). 关于青藏高原东北缘壳幔结构, 前人已经开展了大量研究. Wang等(2007)通过垂直反 射地震方法发现松潘-甘孜块体东部地壳较厚 $(\sim 62 \mathrm{~km})$, 并观测到较低的PmP波振幅, 他们认为松潘甘孜块体东部下地壳存在物质流动; Deng等(2015)通 过面波和接收函数联合反演发现在松潘-甘孜地块下 方地壳较厚 $(\sim 60 \mathrm{~km})$ 且在 $20 \sim 40 \mathrm{~km}$ 深度处存在明显的 低速异常，他们认为该区域下方在中地壳存在部分熔 融; 常利军等(2008)通过剪切波分裂研究发现青藏高 原东北缘方位各向异性快波方向基本上呈 NW-SE方 向, 快波方向与地壳运动速度场方向基本相同, 他们认 为青藏高原东北缘的各向异性层主要分布在上地幔; Huang和Zhao(2006)、Lei和Zhao(2016)、Zhang等 (2018)、董兴朋和滕吉文(2018)的层析成像研究结果 揭示青藏高原东北缘内的松潘-甘孜地块和羌塘地块 下方岩石圈为弱的岩石圈, 其表现出低速异常, 周边稳 定块体(如阿拉善地块、鄂尔多斯地块和四川盆地)下
方岩石圈为冷的岩石圈, 表现出高速异常; Huang和 Zhao(2006)、Lei和Zhao(2016)、Li和Song(2018)和 Li 等(2021)的成像结果显示青藏高原东北缘的松潘-甘孜 地块南部下方上地幔中存在向北俯冲的印度板块. 但 目前关于青藏高原东北缘深部结构的研究，在一些关 键问题上仍存在争议, 具体表现为三个方面: (1) 秦岭 褶皱带上地幔顶部是否存在高速异常. Zhang等(2018) 的远震 $\mathrm{S}$ 波层析成像结果显示秦岭褶皱带下方上地幔 顶部表现出明显的高速异常. 然而, Lei和Zhao(2016)、 董兴朋和滕吉文(2018)通过远震P波层析成像发现秦 岭褶皱带下地壳和上地幔顶部表现出明显的低速异 常. (2) 青藏高原东北缘上地幔各向异性是否由上地幔 流引起. Chang等(2017)通过剪切波分裂和GPS观测发 现青藏高原东北缘大部分地区方位各向异性快波方向 和地表应力场方向的空间分布一致，因此认为该区域 方位各向异性主要源于岩石圈的挤压变形, 而并非上 地幔流. 但小尺度的剪切波分裂研究表明, 青藏高原 东北缘东部地区存在壳幔解耦现象, 这种现象暗示着 青藏高原东北缘部分区域上地幔可能存在上地幔流, 如Huang等(2008)观测到渭河断陷南部和秦岭造山带 南部具有较强的东西向方位各向异性, 这种强各向异 性难以仅仅通过岩石圈变形解释，而需考虑地幔流的 贡献. Gao等(2019)发现松潘-甘孜地块东部和秦岭褶 皱带西部具有双层各向异性特征，表明地壳和上地幔 具有不同的变形机制，上地幔各向异性可能有上地幔 流的贡献. (3) 青藏高原东北缘的昆仑断裂下方是否 存在俯冲的印度板块. Wei等(2012)通过地震P波层析 成像反演了东亚地区地幔结构, 发现青藏高原东北缘 上地幔顶部 $(100 \sim 300 \mathrm{~km})$ 存在近水平分布的高速异常, 该高速异常北缘接近班公-怒江缝合带, 他们认为该高 速异常为印度板块, 并且印度板块以近水平状向北延 伸至青藏高原东北缘下方, 其俯冲前缘接近班公-怒江 缝合带. Lei和Zhao(2016)同样通过远震P波层析成像, 发现青藏高原东北缘昆仑山下方地幔转换带广泛分布 着高速异常, 他们认为该高速异常体为印度板块, 其北 缘接近昆仑断裂. 另外面波层析成像( $\mathrm{Li}$ 等, 2021)显示 青藏高原东北缘金沙江缝合带下方上地幔顶部存在印 度板块, 向北俯冲的印度板块前缘并未到达昆仑断裂 下方.

本文通过反演青藏高原东北缘下方壳幔P波速度 和径向各向异性结构, 为解决上述争议提供新约束. 地 


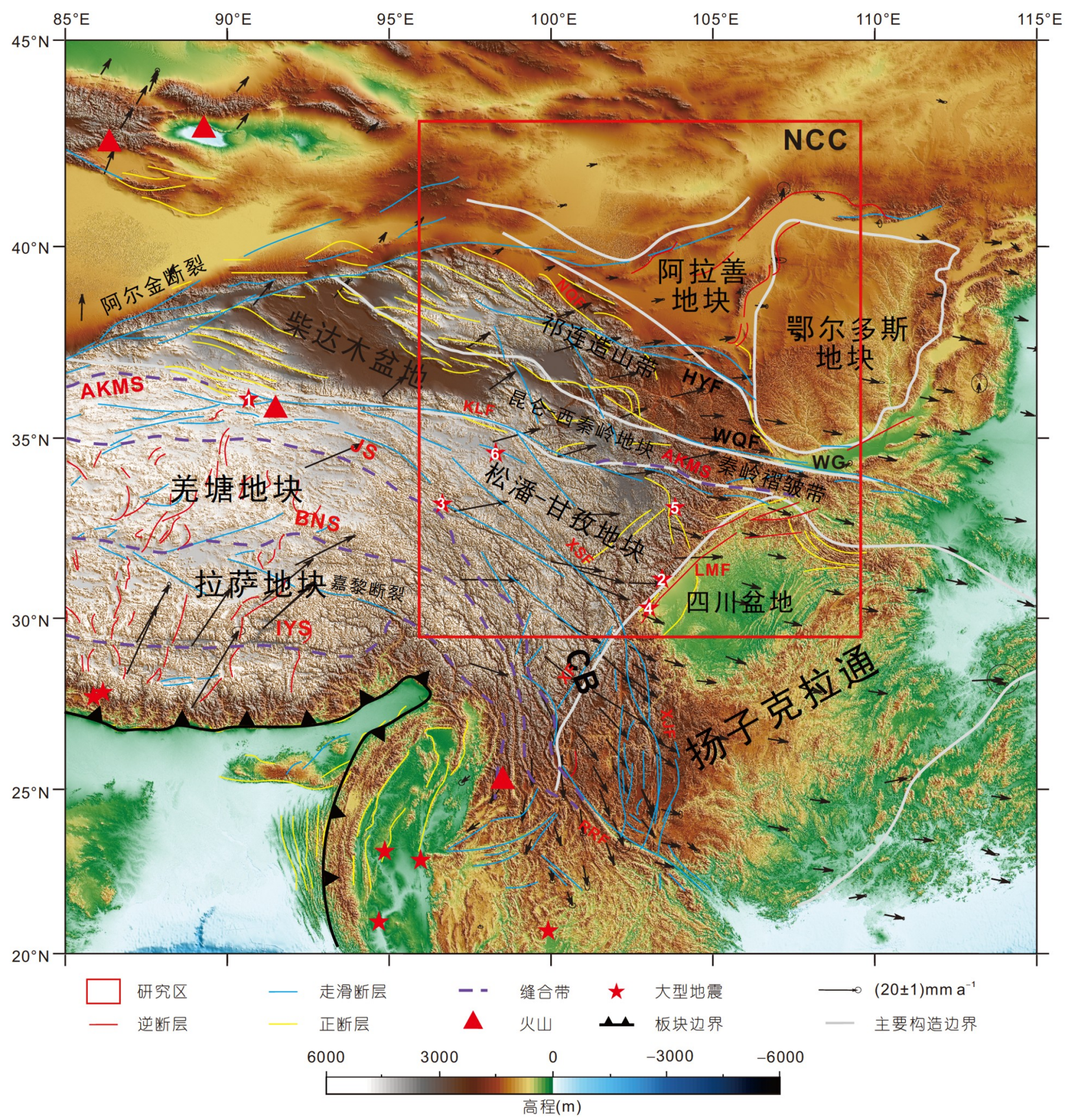

图 1 青藏高原东北缘及周边构造图

红色方框代表研究区. 红五角星代表青藏高原及周边地区2001 2021年以来震级大于 $M_{\mathrm{s}} 7.0$ 的地震. 图中由数字1 6标出的五角星分别代表: 2001 年 $M_{\mathrm{s}} 8.1$ 昆仑山口西地震、2008年 $M_{\mathrm{s}} 8.0$ 汶川地震、2010年 $M_{\mathrm{s}} 7.1$ 玉树地震、2013年 $M_{\mathrm{s}} 7.0$ 芦山地震、2017年 $M_{\mathrm{s}} 7.0$ 九寨沟地震、2021年 $M_{\mathrm{s}} 7.4$ 青海玛多地震. 黑色箭头代表GPS速度场(相对于稳定的欧亚板块)(Zhao等, 2015). 红色三角形代表青藏高原及周边火山. AKMS, 阿尼玛 卿-昆仑山缝合带; BNS, 班公湖-怒江缝合带; CB, 川滇地块. HYF, 海原断裂; IYS, 印度-雅鲁藏布江缝合带; JS, 金沙江缝合带; KLF, 昆仑断裂; LMF, 龙门山断裂; NCC, 华北克拉通; NQF, 北祁连断裂; RRF, 红河断裂; WG, 渭河地堑; WQF, 西秦岭断裂; XF, 小金河断裂; XJF, 小江断裂; XSF, 鲜水河断裂; 断层数据及缝合带数据来自于Taylor和Yin(2009)

震各向异性是地震波传播速度与方向有关的性质，通 过研究地震各向异性, 使我们能够了解地壳和地幔中
物质流动以及过去和现在的变形过程(Zhao和Hua, 2021). 一般来说, 上地壳的地震各向异性主要由充液 
微裂隙在应力作用下定向排列而引起(Crampin和Peacock，2005); 而下地壳和上地幔的各向异性是由应变 导致地幔矿物 (如橄榄石) 的晶格优势排列引起的 (Zhang和Karato，1995; Tatham等，2008; Zhao和Hua, 2021). 地震各向异性可分为方位各向异性和径向各向 异性，研究者常通过剪切波分裂方法研究地壳或上地 幔方位各向异性，这种方法可揭示地壳或上地幔水平 向的流变情况，但得到的各向异性反映的是地壳或上 地幔整体各向异性，缺乏各向异性的深度信息. 径向 各向异性也可用于研究壳幔的流变性，通过远震P波 走时反演可获得径向各向异性的深度分布特征(Wang 和Zhao, 2013; Wang等, 2014), 从而确定各向异性的可 能来源, 这将有助于理解壳幔变形的深部动力学过程. 正径向各向异性 $\left(V_{\mathrm{Ph}}>V_{\mathrm{Pv}}, V_{\mathrm{Ph}}\right.$ 为水平向 $\mathrm{P}$ 波速度, $V_{\mathrm{Pv}}$ 为 垂直向 $\mathrm{P}$ 波速度)或负径向各向异性 $\left(V_{\mathrm{Ph}}<V_{\mathrm{Pv}}\right)$ 则可反映 物质水平或垂直流动、变形等重要特征(Zhang和Karato, 1995; Karato等, 2008), 如地壳中的正(负)径向各向 异性可以反映地壳中水平向(垂直向)应力、裂缝或物 质流(Backus，1962；Leary等，1990; Hacker等，2014; Matharu等, 2014; Jaxybulatov等, 2014; Harmon和Rychert, 2015; Almqvist和Mainprice, 2017; Jiang等, 2018; Lynner等，2018), 上地幔的正径向各向异性通常与软 流圈流动有关(Sharma等, 2021), 负径向各向异性常出 现在山脊和地幔柱下方，常与垂直地幔流有关(Romanowicz和Wenk, 2017). 因此探测地球内部径向各向异 性结构可以为研究地壳和地幔动力学过程提供新 约束.

然而，目前关于青藏高原东北缘及周边地区的层 析成像研究所采用的方法大多是基于传统射线理论, 在成像时采用伪弯曲法(Pseudo-bending Method)计算 射线路径. 在复杂非均匀模型中，伪弯曲法难以精确 地确定射线路径(Liu和Tong, 2021), 而通过数值求解 程函方程可准确获得非均匀介质中的射线路径(Rawlinson和Sambridge，2005; Rawlinson等，2006；Liu和 Tong，2021)，因此本文利用基于程函方程的成像方法 研究青藏高原东北缘及周边地区速度和径向各向异性 结构. 利用布设在青藏高原东北缘及周边地区的密集 流动和固定宽频带地震台记录的远震波形数据，通过 基于程函方程的成像方法反演互相关走时数据，本文 得到了青藏高原东北缘下方深度至 $800 \mathrm{~km}$ 的壳幔P波 速度和径向各向异性结构模型，并讨论青藏高原东北
缘壳幔结构研究中存在的争议, 为青藏高原的隆升与 变形机制提供新约束.

\section{2 数据与方法}

\section{1 数据}

本文选取的研究区域范围为 $29.5^{\circ} \mathrm{N} 43^{\circ} \mathrm{N}, 96^{\circ} \mathrm{E}$ $\sim 109.5^{\circ} \mathrm{E}$, 所用的数据来源于三个台网. 第一个台网是 川西流动地震台(Liu等, 2014), 该台网一共有297个地 震台, 其中99个在本研究区域, 记录时间自2006年10月 至2008年12月; 第二个台网是喜马拉雅二期地震台, 该 台网一共有 674 个地震台(中国地震科学台阵, 2006; 喜 马拉雅地震科学台阵, 2011; 常利军等, 2016), 本研究 使用其中 671 个地震台记录的波形数据，记录时间从 2013年10月至2016年6月; 第三个台网是中国地震台 网的固定地震台(郑秀芬等, 2009), 本研究区域中固定 台一共有 151 个，记录时间从2009年1月至2020年8月. 因此本研究一共使用了 921 个地震台, 这些台站的分 布如图2a所示. 整体而言, 研究区内的阿拉善块体、 祁连造山带、鄂尔多斯块体和四川盆地台站分布密度 较高, 平均台站间距 $30 \mathrm{~km}$. 相对而言, 松潘-甘孜地块 东部和㒸塘地块东南部台站较为稀疏，平均台站间距 $\sim 100 \mathrm{~km}$.

根据ISC(International Seismological Centre; http:// www.isc.ac.uk/)、IRIS(Incorporated Research Institutions for Seismology; https://www.iris.edu/hq/)和USGS (U.S. Geological Survey; https://eart-hquake.usgs.gov/) 提供的全球地震目录，排除上述不同机构提供的全球 地震目录中震源参数相差较大的地震事件后(本文篮 选准则为: 不同机构的地震目录发震时刻相差 $3 \mathrm{~s}$ 以内, 震中相差 $0.1^{\circ}$ 以内, 震源深度相差在 $10 \mathrm{~km}$ 以内), 优先 选取ISC提供的地震目录以确定地震事件的震源参数 (由于ISC地震目录进行了地震重定位, 因此震源参数 精度较高). 根据篎选后的地震目录选取震中距在 $30^{\circ}$ $\sim 90^{\circ}$ 之间的远震事件, 远震选取准则要求远震震级大 于M5.5, 每个远震事件至少被 10 个地震台记录. 根据 以上标准, 本研究一共选取了 667 个远震事件, 其分布 如图 $2 b$ 所示. 从图 $2 b$ 可以看出, 远震分布具有较好的方 位覆盖度.

本文的数据处理主要分为三步. 首先, 根据已选取 的远震事件，截取远震发震时刻前300s和后2000s 之间 

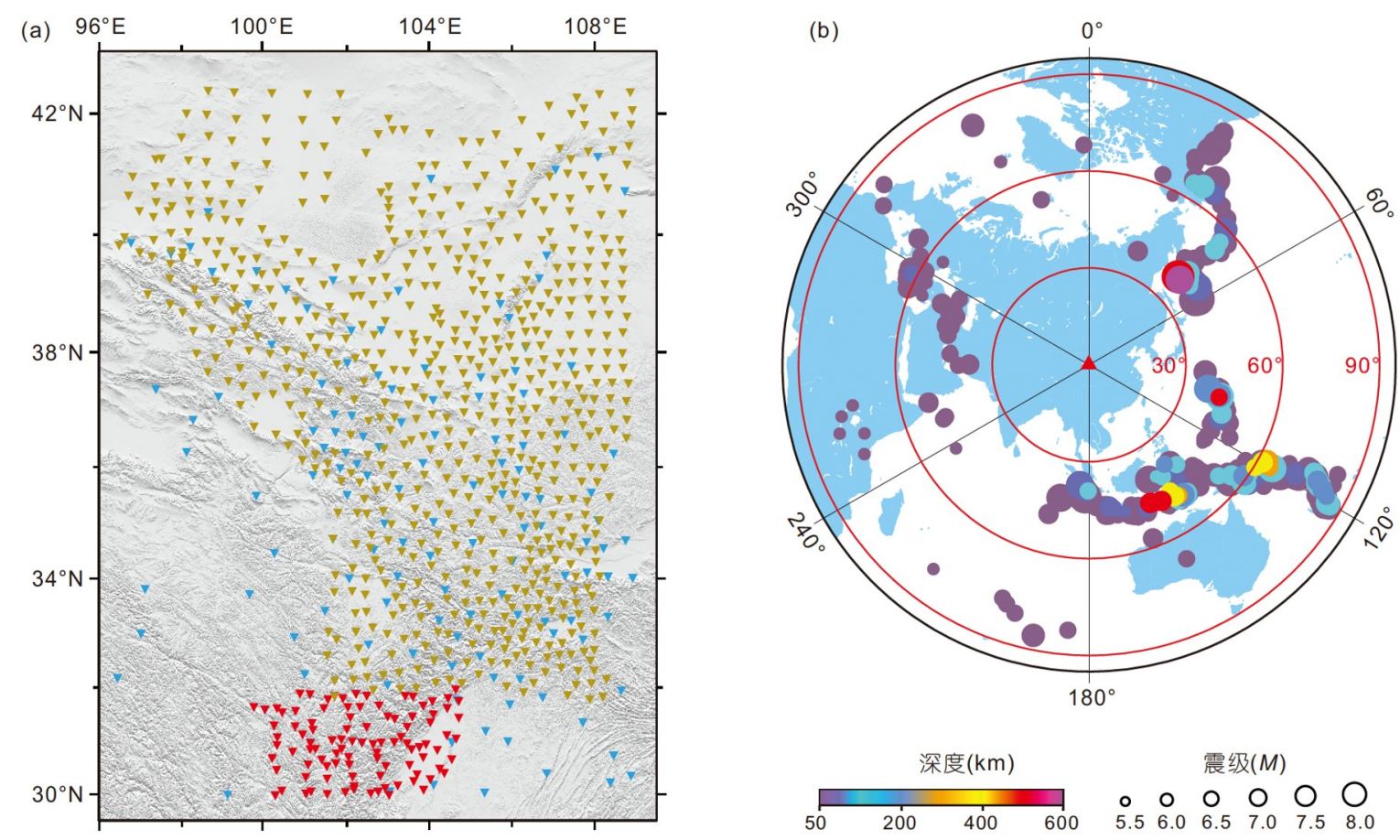

图 2 宽频地震台(a)与远震(b)分布图

(a)中红色三角形代表川西流动地震台站, 黄色三角形代表喜马拉雅二期流动地震台站, 蓝色三角形代表固定地震台站. (b)中实心圆点代表远 震事件, 大小表示震级, 颜色表示深度; 红色三角形表示研究区中心; 三个红色同心圆圈分别表示离研究区域 $30^{\circ} 、 60^{\circ}$ 和 $90^{\circ}$ 的等距线

的波形数据, 对原始的远震波形数据进行去均值、去 尖灭、去线性趋势以及去仪器响应等处理, 然后对波 形数据带通滤波，滤波范围为 $0.03 \sim 0.3 \mathrm{~Hz}$. 然后，利用 TauP软件(Crotwell等, 1999)计算直达P波理论到时, 参 考理论到时并在滤波后的波形数据中手动截取直达 $\mathrm{P}$ 波波形. 最后, 采用波形多道互相关方法(Multichannel Cross Correlation)(Vandecar和Crosson, 1990; Liu等, 2018)计算远震P波相对走时差，并估计相对走时差的 不确定性. 在反演时, 一方面为了尽量消除模型外部 速度结构非均匀性对成像模型内速度反演的影响，提 高反演结果的精度, 要求做波形互相关的台站对足够 接近，但台站间距过于接近难以保证包含足够多的射 线用于成像; 另一方面为了提高反演结果的可靠性而 必须增加足够多的射线覆盖，这就要求做波形互相关 的台站对间距较大. 因此实际远震成像时需要平衡最 大容许的台间距和射线数目，本文按照Liu等(2019)提 出的 L曲线方法确定最优台间距. 研究区内关于最大 台站间距和台站对数量的 $\mathrm{L}$ 曲线如图 $3 \mathrm{a}$ 所示, 最大台 站间距为 $1.0^{\circ}$ 所对应的点(图3a中的红色实心圆)为 L曲 线的拐点，因此本文选择做波形互相关的最大台间距
为 $1.0^{\circ}$. 同理, 最小容许波形互相关系数和相对走时数 据数目之间同样存在折衷关系, 关于互相关系数和相 对走时数据数目的 $\mathrm{L}$ 曲线如图 $3 \mathrm{~b}$ 所示, 图 $3 \mathrm{~b}$ 中 $\mathrm{L}$ 曲线的 拐点对应的互相关系数为 0.96 , 因此本文选择 0.96 作为 互相关系数阀值. 在台间距和互相关系数的共同限定 下, 最终得到约 77 万对相对走时差.

\section{2 方法}

本文利用基于程函方程的远震成像方法(Liu和 Tong, 2021)反演青藏高原东北缘下方壳幔速度和径向 各向异性结构模型. 任意非均匀介质中的程函方程可 表示为

$|\nabla T|=S$,

式中, $T$ 为走时场, $S$ 为介质慢度. 在已知 $S$ 的条件下, 通 过数值方法求解式(1)可获地震波的空间走时场. 对于 $\mathrm{P}$ 波径向各向异性成像, 假设六方各向异性介质具有垂 直的对称轴, P波慢度可以表示为(Backus, 1965; Raitt 等, 1969; Hearn, 1996; Eberhart-Phillips和Henderson, 2004) 

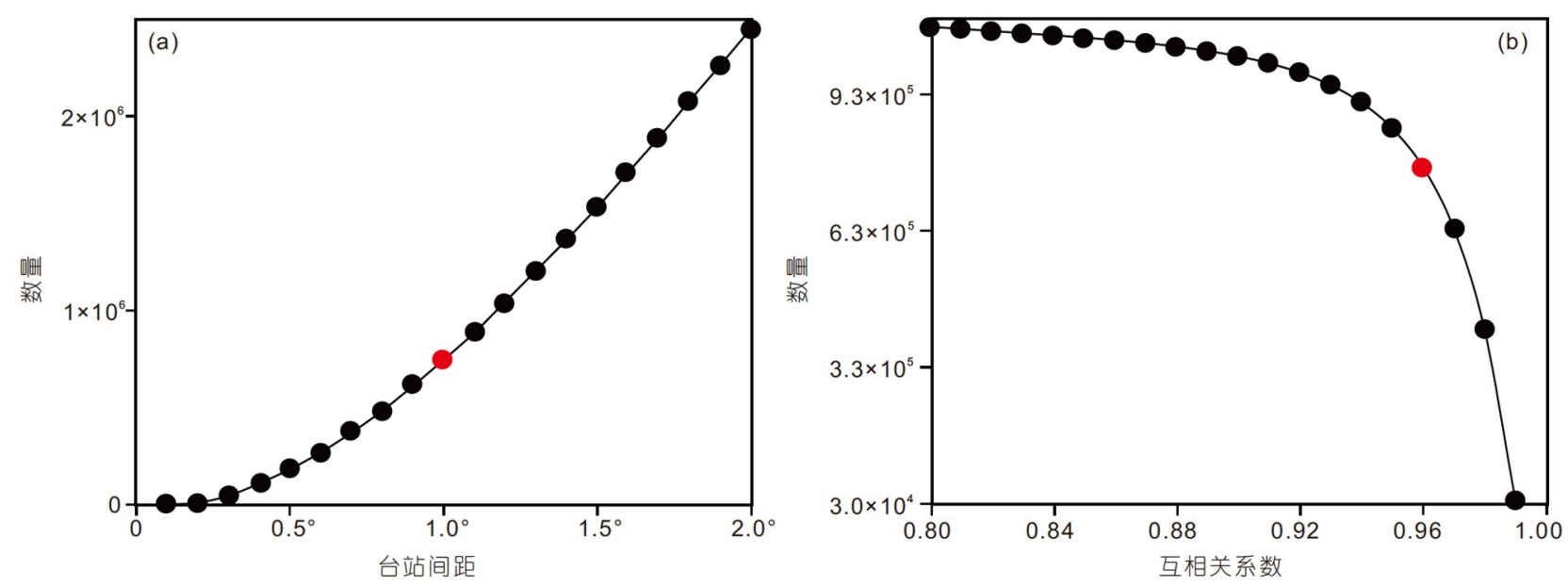

图 3 L曲线用于确定最大容许台间距和最小容许互相关系数

(a) 研究区内关于台间距和台站对数量的 $\mathrm{L}$ 曲线, 红色实心圆代表最优台站间距 $\left(1.0^{\circ}\right)$; (b) 关于互相关系数和相对走时数量的 $\mathrm{L}$ 曲线, 红色实心 圆代表最优互相关系数值 $(0.96)$

$S=S_{0}(1+M \cos (2 i))$,

式中, $S$ 是各向异性介质中的慢度, $S_{0}$ 是介质的平均慢 度, $M$ 是径向各向异性强度, $i$ 是射线入射角. 根据射线 成像理论，观测方程可表示为(Shearer，1999; Zhao等, 2016)

$$
\begin{aligned}
R_{m n h}= & \left(T_{m n}^{\mathrm{obs}}-T_{m h}^{\mathrm{obs}}\right)-\left(T_{m n}^{\mathrm{syn}}-T_{m h}^{\mathrm{syn}}\right) \\
\approx & \sum_{p n}\left(\frac{\partial T}{\partial V_{\mathrm{p}}} \Delta V_{\mathrm{p}}\right)+\sum_{q n}\left(\frac{\partial T}{\partial M_{q}} \Delta M_{q}\right) \\
& -\sum_{p h}\left(\frac{\partial T}{\partial V_{\mathrm{p}}} \Delta V_{\mathrm{p}}\right)-\sum_{q h}\left(\frac{\partial T}{\partial M_{q}} \Delta M_{q}\right),
\end{aligned}
$$

式中, $R_{m n h}$ 为第 $m$ 个事件到第 $n$ 个和第 $h$ 个台站的相对走 时残差, $T$ 为到时, 上标obs和syn分别代表观测和理论 到时, 下标 $m n$ 和 $m h$ 分别为第 $m$ 个事件到第 $n$ 个台站和 第 $h$ 个台站的到时, $\Delta V$ 和 $\Delta M$ 分别为速度扰动和径向各 向异性扰动, $p$ 和 $q$ 分别表示第 $p$ 个和第 $q$ 个反演网格点. 公式(3)需要台站处的走时和成像模型内的远震射线 路径. 本文分三步得到走时和射线路径. 首先, 计算层 状地球模型中的走时场(Crotwell等，1999)，用于构造 远震入射边界条件; 其次, 利用满足熵的快速行进法 (Fast Marching Method)(Rawlinson和Sambridge, 2005; Sethian和Popovici, 1999)求解公式(1), 并计算地震波走 时场; 最后, 从台站出发沿着走时场的负梯度方向计算 台站至模型边界的远震射线路径(Liu等, 2019). 反演P
波速度和径向各向异性结构需要求解如下带阻尼的最 小二乘问题(Tong等, 2014; Liu等, 2018):

$$
E(\mathbf{X})=(\mathbf{A X}-\mathbf{b})^{\mathrm{T}} \mathbf{C}_{\mathrm{d}}^{-1}(\mathbf{A} \mathbf{X}-\mathbf{b})+\eta \mathbf{X}^{\mathrm{T}} \mathbf{C}_{\mathrm{m}}^{-1} \mathbf{X},
$$

式中, $\mathbf{A}$ 是灵敏度矩阵, $\mathbf{X}$ 是离散模型, $\mathbf{C}_{\mathrm{d}}$ 为数据协方差 矩阵, $\mathbf{C}_{\mathrm{m}}$ 为模型协方差矩阵, $\eta$ 是阻尼因子, $\mathbf{b}$ 是相对到 时残差向量. $\mathbf{A}$ 中的每一行由公式(3)中的右端项构成. 通过共轭梯度方法(Conjugate Gradient Method)(Hestenes和Stiefel, 1952)求解式(4), 即可获得P波速度和径 向各向异性参数.

通过大量的检测板测试用于确定优化的反演参数 化网格(Liu等, 2018). 用于P波速度模型参数化的网格 水平方向间隔为 $1.6^{\circ}$, 并在 $30 、 80 、 150 、 250 、 350$ 、 450、550和700 km深度处设置网格点; 用于径向各向 异性模型参数化的网格水平方向间隔为 $1.8^{\circ}$, 并在 40、170、250、350、410和660km深度处设置网格点. $\mathrm{P}$ 波速度模型和径向各向异性模型同时反演, 并采用地 球一维速度模型AK135(Kennett等，1995)作为初始模 型. 由于青藏高原内部及周边地区地壳结构具有不均 匀性(Zhang等, 2014), 因此本研究采用CRUST1.0 (Laske等, 2013)用于地壳校正.

在反演过程中未考虑先验模型信息, 因此 $\mathbf{C}_{\mathrm{m}}$ 设置 为单位矩阵 (Liu等, 2018). 将已获得的数据不确定性放 置在 $\mathbf{C}_{\mathrm{d}}$ 的对角线上. 在每一次迭代中通过线性插值方 法将反演网格上的速度扰动和径向各向异性扰动插值 至模型全空间. 为了使得反演稳定收敛至目标模型, 在 
每一次迭代中通过选取阻尼因子将模型的最大相对扰 动控制在 $1 \%$ 以内. 借鉴 $\mathrm{L}$ 曲线方法获取最优的迭代次 数(图4a), 使得模型方差和数据方差之间达到平衡( $\mathrm{Liu}$ 等，2021), 同时利用误差下降曲线进一步约束迭代次 数(Chen等, 2015). 由图 $4 \mathrm{a}$ 和 $4 \mathrm{~b}$ 可共同确定最优迭代步 为 5 . 图 $4 \mathrm{c}$ 展示了反演前后数据残差直方图, 数据残差 的标准差由最初的 $0.36 \mathrm{~s}$ 减小至 $0.30 \mathrm{~s}$.

\section{3 结果}

\section{1 检测板测试结果}

为了测试成像方法和数据的分辨率，在实际数据 反演之前进行了检测板测试．在初始模型中设置 $\pm 2 \%$ 交替的P波相对速度扰动用于构建 $\mathrm{P}$ 波速度检测板测 试模型; 在模型中设置 $\pm 1.5 \%$ 交替的径向各向异性扰 动用于构建径向各向异性检测板测试模型．检测板测

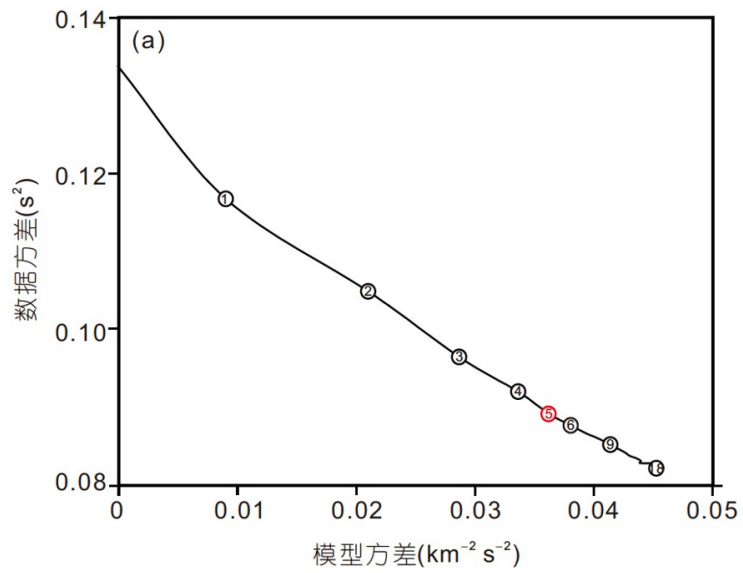

试所用到的参数和随后实际数据反演所用到的参数一 致. 检测板测试所用到的合成数据由FMM计算得到, 并在合成数据中加入 $0.15 \mathrm{~s}$ 的高斯随机噪声用于模拟 实际数据噪声. 图5展示的是 $\mathrm{P}$ 波速度检测板测试水平 切片结果. 可以看出反演结果很好地恢复出速度交替 扰动形态, 总体而言, 当深度超过 $350 \mathrm{~km}$ 以后反演分辨 率最高; 在 $350 \mathrm{~km}$ 深度以上, 模型的西南区域分辨率相 对较低, 主要原因在于该区域台站分布较稀疏(图2a), 除西南区域以外，模型的其他区域分辨率较高. 图6展 示的是P波速度检测板测试垂直切片结果, 结果显示速 度模型在垂向方向上具有较好的分辨率，反演结果能 很好地恢复出研究区内的速度交替扰动形态, 在垂直 方向不存在明显的拖尾效应. 图7展示的是径向各向 异性检测板测试水平切片结果，与P波速度检测板测 试结果相似, 结果显示径向各向异性模型除了在研究 区西南部的分辨率相对较低以外，其他区域分辨率均

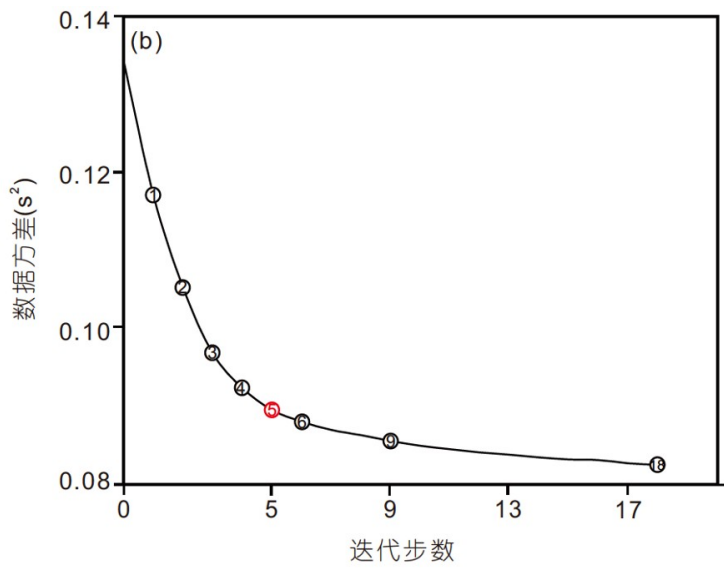

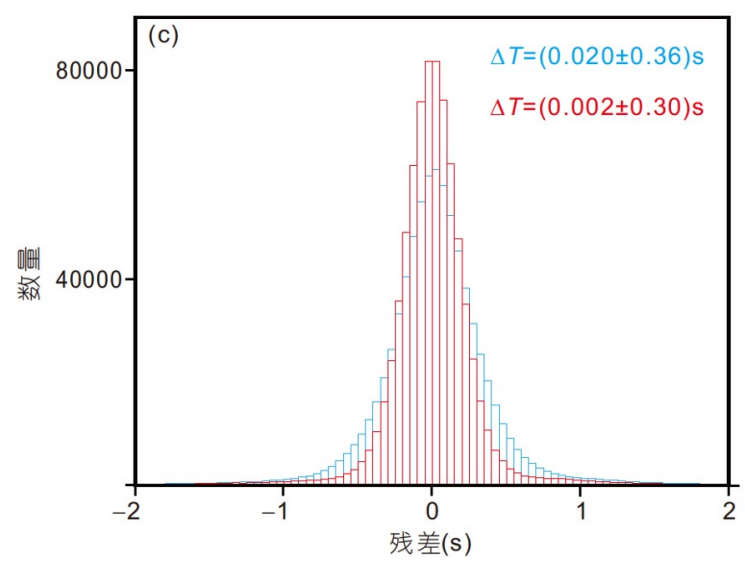

图 4 L曲线、误差下降曲线和数据残差直方图

(a) 关于数据方差和模型方差的L曲线, 空心圆表示迭代步数, 对应的步数标记在空心圆内, 红色空心圆代表最佳迭代步; (b) 数据方差随迭代 步数的下降曲线, 红色空心圆代表最佳迭代步; (c) 走时残差直方图, 蓝色和红色直方图分别代表反演前后走时残差分布 


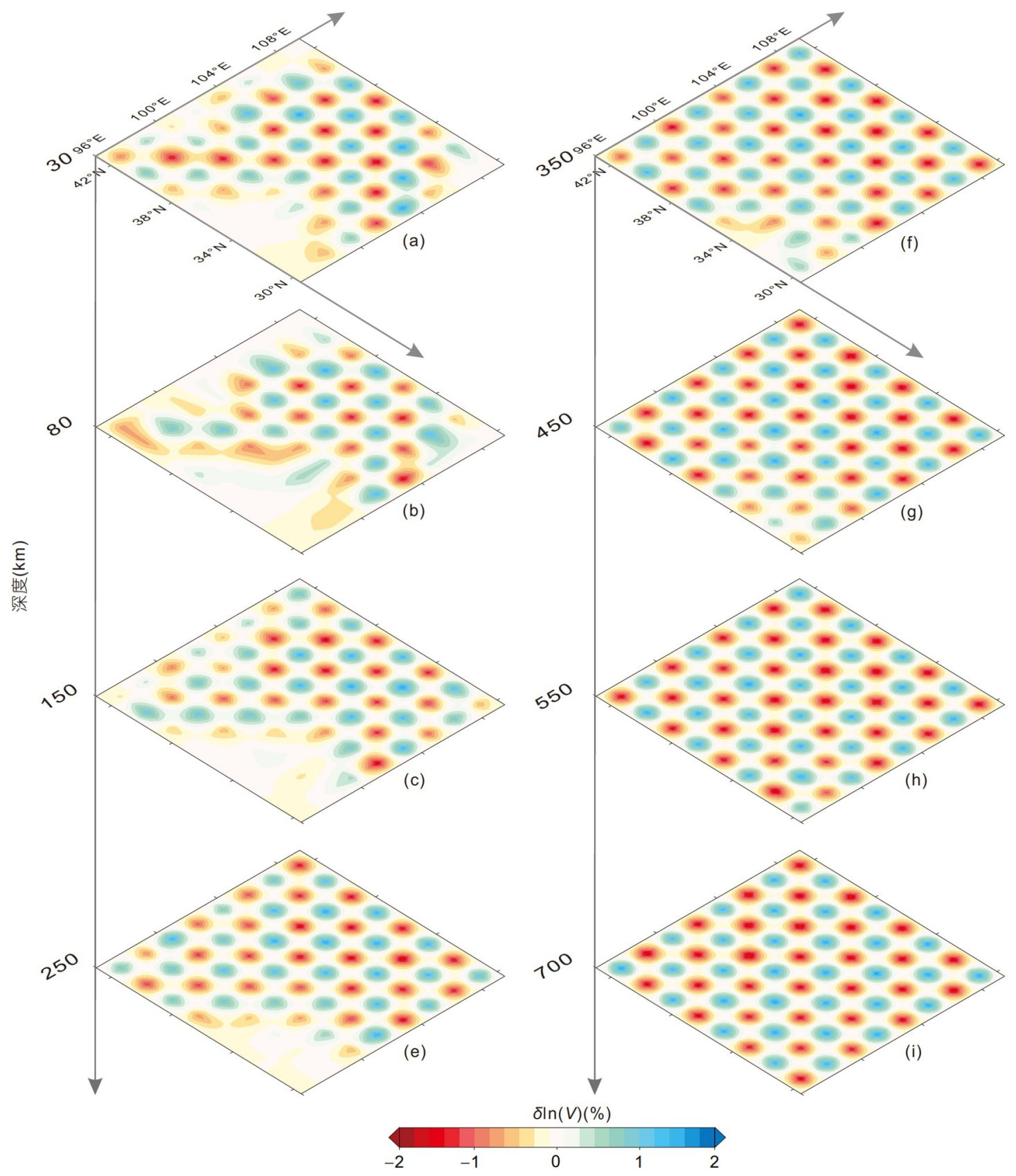

图 5 P波速度模型检测板测试的水平切片结果

水平切片的深度标记在垂直轴的左侧. 速度相对扰动的比例尺标记在图的底部

较高. 图8展示的是径向各向异性检测板测试垂直切片 结果, 在垂直方向同样不存在明显的拖尾效应.

\section{2 水平切片结果}

图9为P波速度相对扰动的水平切片. 如图9a 9c所 示, 30 150km深度处速度异常与地表构造具有很好的
相关性. 由于鄂尔多斯地块、阿拉善地块和四川盆地 为稳定块体，具有较冷的岩石圈，因此这些区域下方 表现出明显的高速异常, 成像结果与块体或盆地内部 表现出弱的地震活动性和具有较少断裂特征相一致. 阿拉善地块下方的高速异常强度要弱于鄂尔多斯地块 和四川盆地，表明在周围块体的挤压作用下阿拉善地 

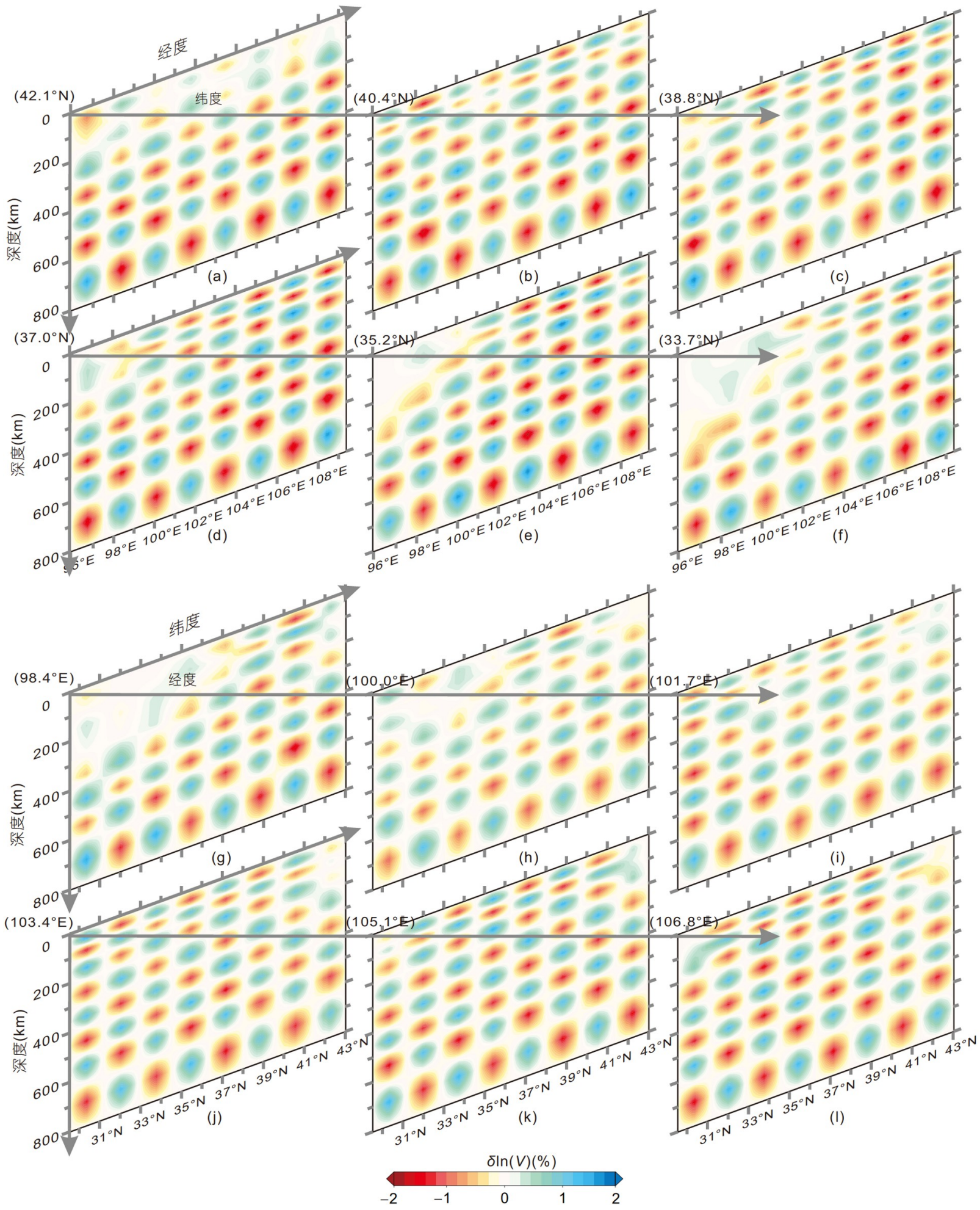

图 6 P波速度模型检测板测试的垂直切片结果

垂直切片的深度标记在垂直轴的左侧, (a) (f) 分别为沿着纬线 $42.1^{\circ} \mathrm{N} 、 40.4^{\circ} \mathrm{N} 、 38.8^{\circ} \mathrm{N} 、 37.0^{\circ} \mathrm{N} 、 35.2^{\circ} \mathrm{N}$ 和 $33.7^{\circ} \mathrm{N}$ 处 $\mathrm{P}$ 波速度模型检测板测试 的垂直切片结果, $(\mathrm{g}) \sim(1)$ 分别为沿着经线 $98.4^{\circ} \mathrm{E} 、 100.0^{\circ} \mathrm{E} 、 101.7^{\circ} \mathrm{E} 、 103.4^{\circ} \mathrm{E} 、 105.1^{\circ} \mathrm{E}$ 和 $106.8^{\circ} \mathrm{E}$ 处 $\mathrm{P}$ 波速度模型检测板测试的垂直切片结果. 速度相对扰动的比例尺标记在图的底部 


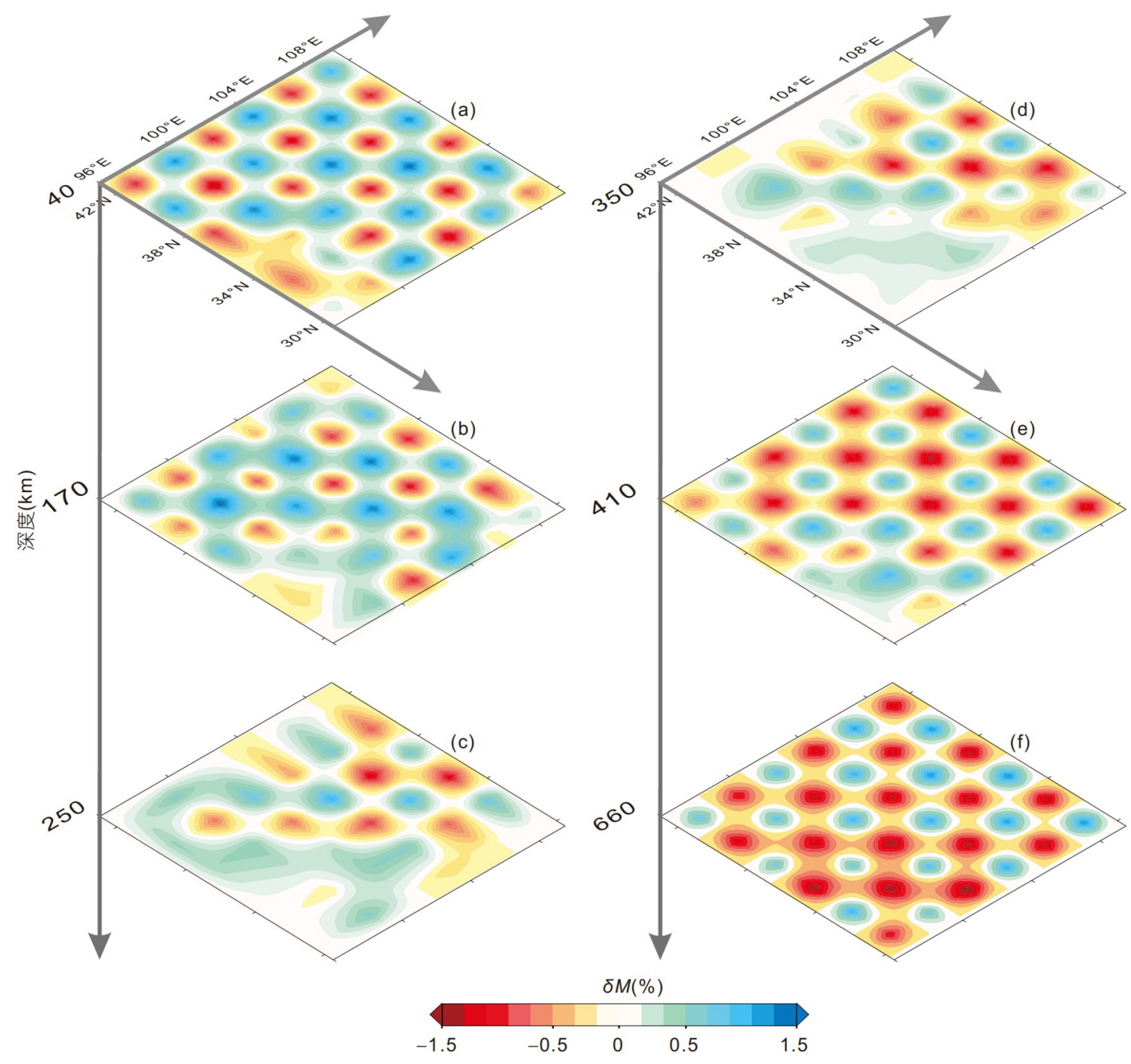

图 7 径向各向异性模型检测板测试的水平切片结果

水平切片的深度在垂直轴的左侧. 径向各向异性强度的比例尺标记在图的底部

块可能正在经历岩石圈的变形和破坏(Zhang等, 2010; Wang等, 2019). 祁连造山带、昆仑-西秦岭地块东部、 秦岭褶皱带西部及松潘-甘孜地块东北部表现出明显 的低速异常. 如图9d所示, 在 $250 \mathrm{~km}$ 深度处速度异常与 浅部差别较大，虽然鄂尔多斯块体和四川盆地下方表 现出高速异常，但高速异常的幅度比浅部弱，分布范 围比浅部小; 虽然祁连造山带下方表现出低速异常, 但低速异常的幅度也比浅部弱，分布范围也比浅部小; 此外, 阿拉善地块下方的高速异常消失, 川滇块体北部 下方表现出明显的高速异常. 如图9e所示, 在 $350 \mathrm{~km}$ 深 度处, 川滇块体北部下方仍表现出明显的高速异常, 该 高速异常可能延伸至450km深度处(图9f). 当深度到达
550 和 $700 \mathrm{~km}$ 时，高低速异常的幅度较小，在研究区内 未发现明显的速度异常体.

地壳至上地幔的P波速度径向各向异性反演结果 如图10所示. 在 $40 \mathrm{~km}$ 深度处(图10a)，祁连造山带、松 潘-甘孜地块东部以及秦岭褶皱带西部表现出正的径 向各向异性. 鄂尔多斯地块和四川盆地下方地球介质 表现出负的径向各向异性, 说明稳定块体下地壳或下 地壳底部表现出“化石”径向各向异性(Li等, 2021). 图 $10 \mathrm{~b}$ 中显示的径向各向异性总体上与图10a相似。鄂尔 多斯地块和四川盆地下方仍表现出负的径向各向异 性，说明这些区域下方岩石圈同样保持着“化石”径向 各向异性. 祁连造山带和松潘-甘孜地块东部表现出正 

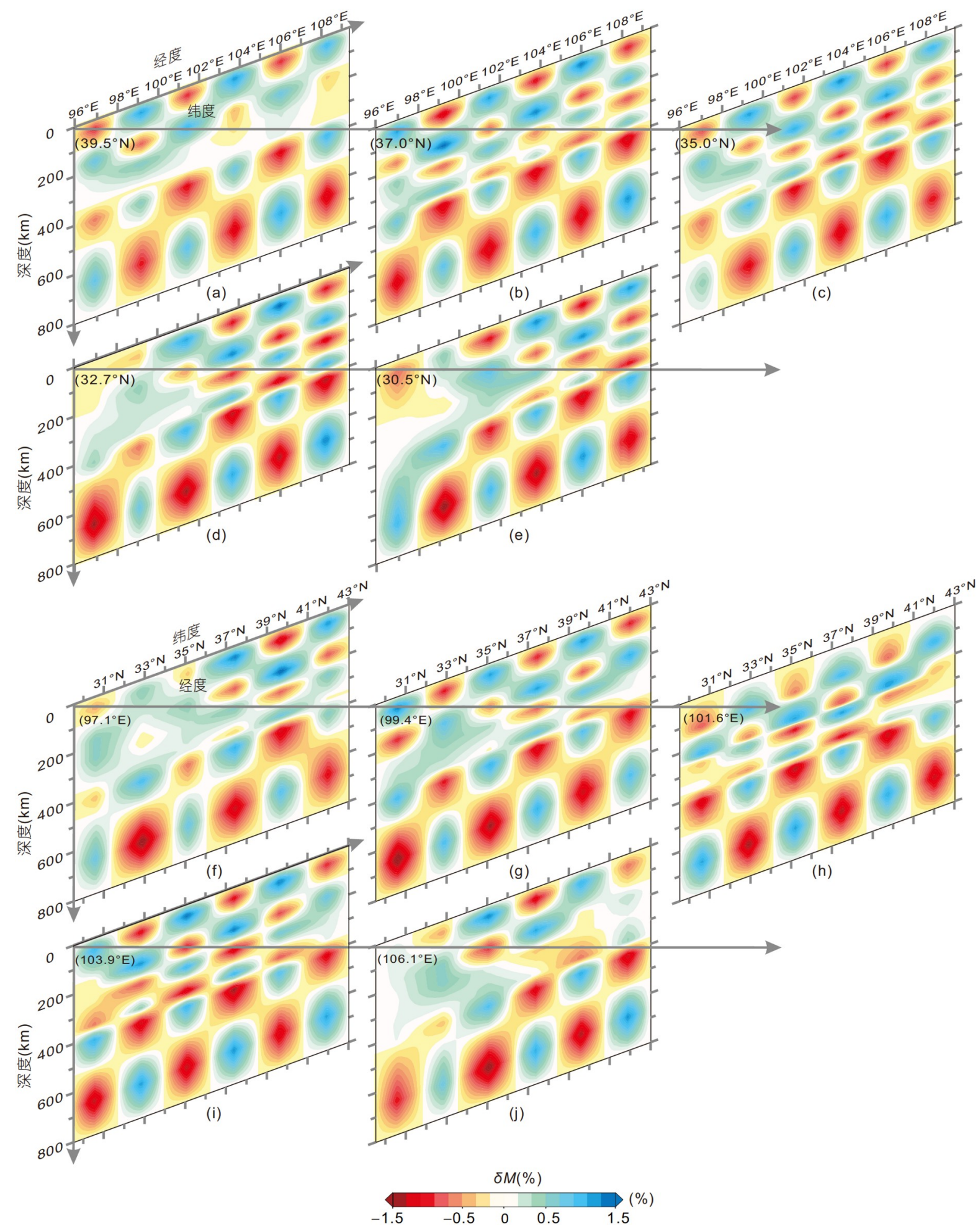

图 8 径向各向异性模型检测板测试的垂直切片结果

(a) ( (e) 分别为沿着纬线 $39.5^{\circ} \mathrm{N} 、 37.0^{\circ} \mathrm{N} 、 35.0^{\circ} \mathrm{N} 、 32.7^{\circ} \mathrm{N}$ 和 $30.5^{\circ} \mathrm{N}$ 处径向各向异性的检测板测试垂直切片结果; (f) (j) 分别为沿着经线 $97.1^{\circ} \mathrm{E} 、 99.4^{\circ} \mathrm{E} 、 101.6^{\circ} \mathrm{E} 、 103.9^{\circ} \mathrm{E}$ 和 $106.1^{\circ} \mathrm{E}$ 处径向各向异性模型检测板测试的垂直切片结果. 垂直切片的深度标记在垂直轴的左侧, 径向 各向异性扰动的比例尺标记在图的底部 

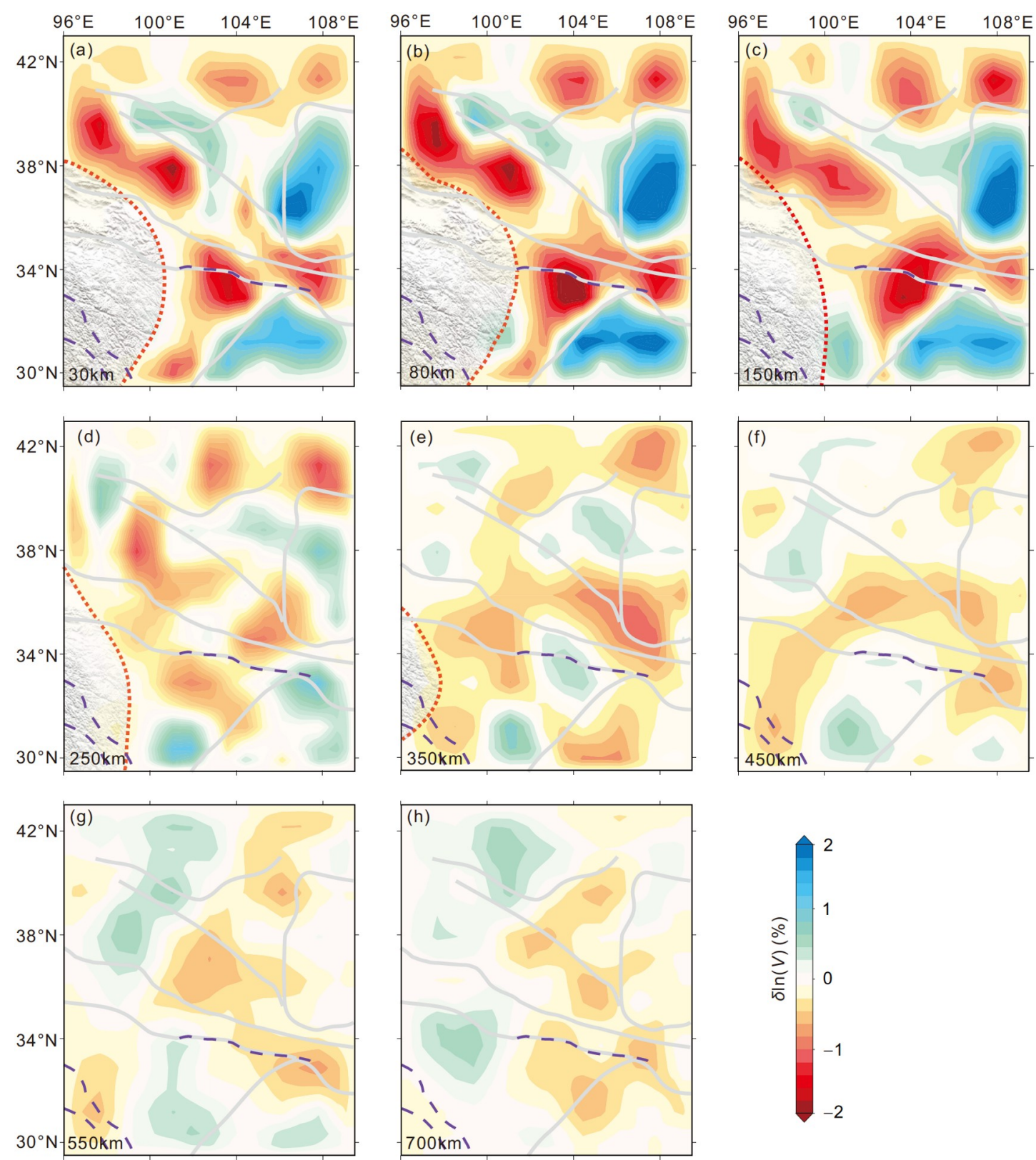

图 9 水平切片上的P波速度反演结果

水平切片对应的深度显示在子图的左下角. 灰色实线代表研究区域的主要构造边界, 紫色虚线代表缝合线. 速度相对扰动幅值的比例尺显示 在图的右下角

的径向各向异性. 图10c显示在 $250 \mathrm{~km}$ 深度处鄂尔多斯 地块和四川盆地北部下方仍保持着负径向各向异性, 但径向各向异性的强度明显低于图10a和10b; 祁连造 山带和松潘-甘孜地块东缘下方表现出微弱的正径向 各向异性 $(<0.5 \%)$, 较难分辨这种微弱的各向异性是实 际结构特征还是随机成像假象. 当深度超过 $250 \mathrm{~km}$ 以 后(图10d 10f), 研究区内的径向各向异性几乎消失.

\section{3 垂直切片结果}

图11显示的是沿着主要构造带的垂直切片结果. 高速异常和低速异常的分布与地表地形有较好的对应 关系: 海拔较高的区域(或禇皱带)对应低速异常; 海拔 

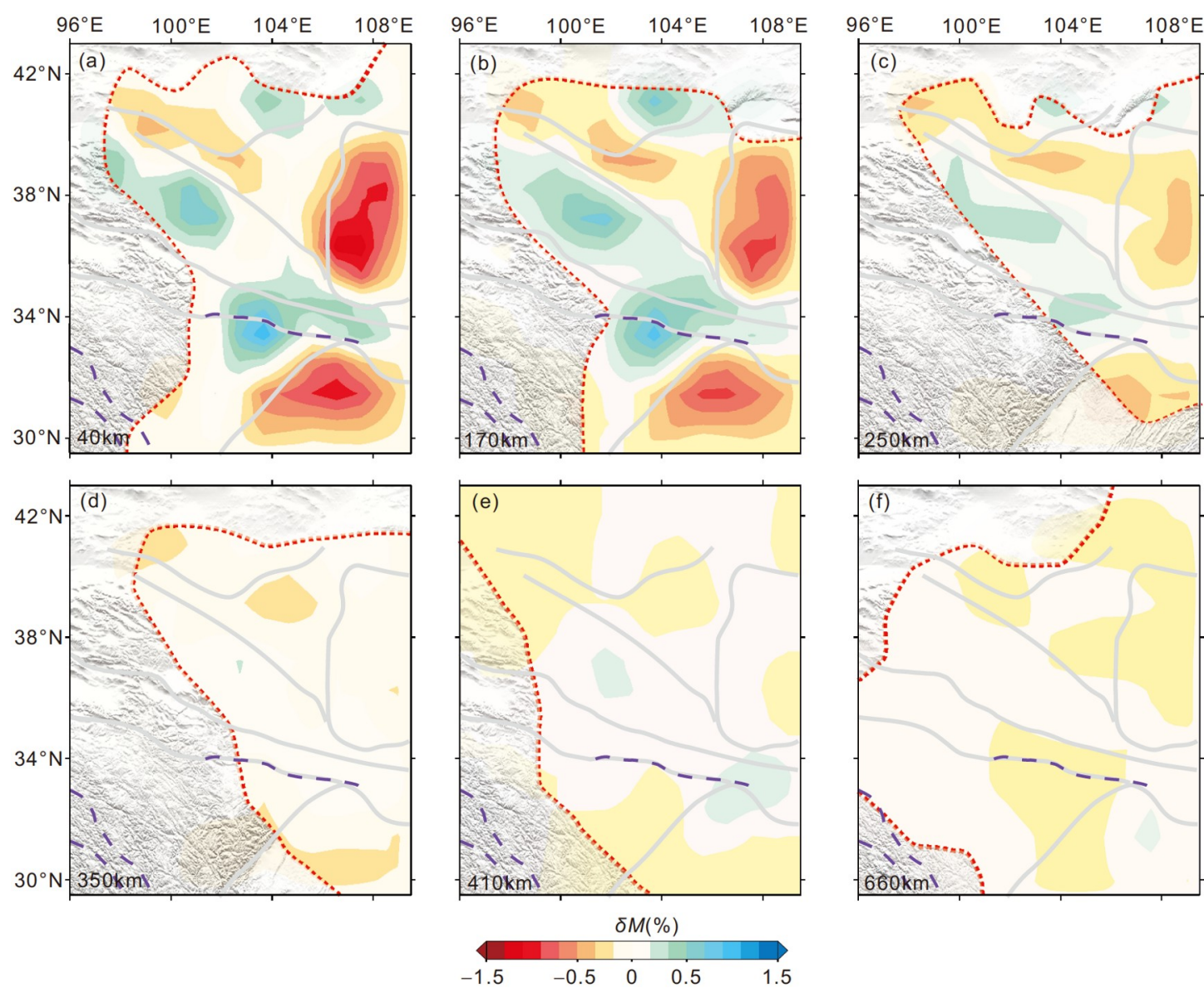

图 10 水平切片上的P波速度径向各向异性反演结果

水平切片对应的深度显示在子图的左下角. 径向各向异性扰动幅度的比例尺显示在图的底部

较低的区域(或稳定的地块)对应于高速异常. 这些特 征与前人研究基本一致(Lei和Zhao，2016；Zhang等， 2018). 图11a显示，四川盆地和松潘-甘孜地块下方岩 石圈分别表现出显著的高速异常和低速异常，龙门山 断裂正好分隔了这些高低速异常，这表明龙门山断裂 可能深切了岩石圈(Zhang等, 2010; Wang等, 2019), 龙 门山断裂发生了较多强震, 如 2008 年 $M_{\mathrm{s}} 8.1$ 汶川地震, 2013年 $M_{\mathrm{s}} 7.0$ 芦山地震(图1), 这些地震都发生在高低 速块体过渡的边界上. 图11b显示秦岭褶皱带表现为 明显的低速异常, 低速异常向下延伸至 $200 \mathrm{~km}$ 左右. 图 $11 \mathrm{c}$ 显示川滇块体北部下方存在从上地幔顶部延伸至 地幔转换带的高速异常，该高速异常可能为北向俯冲 的印度板块(Lei和Zhao, 2016; Li等, 2021). 松潘-甘孜 地块东北部和秦岭褶皱带西部下方 $300 \mathrm{~km}$ 以上均表现 为明显的低速异常，该低速异常自东北方向一直延伸 至鄂尔多斯块体岩石圈下方 $400 \mathrm{~km}$ 深度处. 图 $11 \mathrm{~d}$ 显
示松潘-甘孜地块东北部和秦岭褶皱带下方均表现为 强烈的低速异常，但秦岭褶皱带下方低速异常向下延 伸深度较浅 $(200 \mathrm{~km})$. 图11e显示秦岭褶皱带下方的低 速体位于鄂尔多斯块体和四川盆地下方的高速异常之 间，该低速体在 $100 \mathrm{~km}$ 深度处表现出较强的负异常扰 动, 在100 300km深度处表现出较弱的负异常扰动.

\section{4 恢复性测试}

为了验证本文 $\mathrm{P}$ 波速度和径向各向异性成像结果 主要特征的可靠性，本文根据成像结果构造了如图12 和图13所示的合成模型. 图12中阿拉善地块、鄂尔多 斯地块和四川盆地下方岩石圈为高速异常, 祁连造山 带、秦岭褶皱带和松潘-甘孜地块东部下方岩石圈为 低速异常，合成模型中异常体相对速度扰动的幅值为 2\%. 图13中祁连造山带、秦岭褶皱带和松潘-甘孜地 块东部下方岩石圈为正的径向各向异性，鄂尔多斯块 

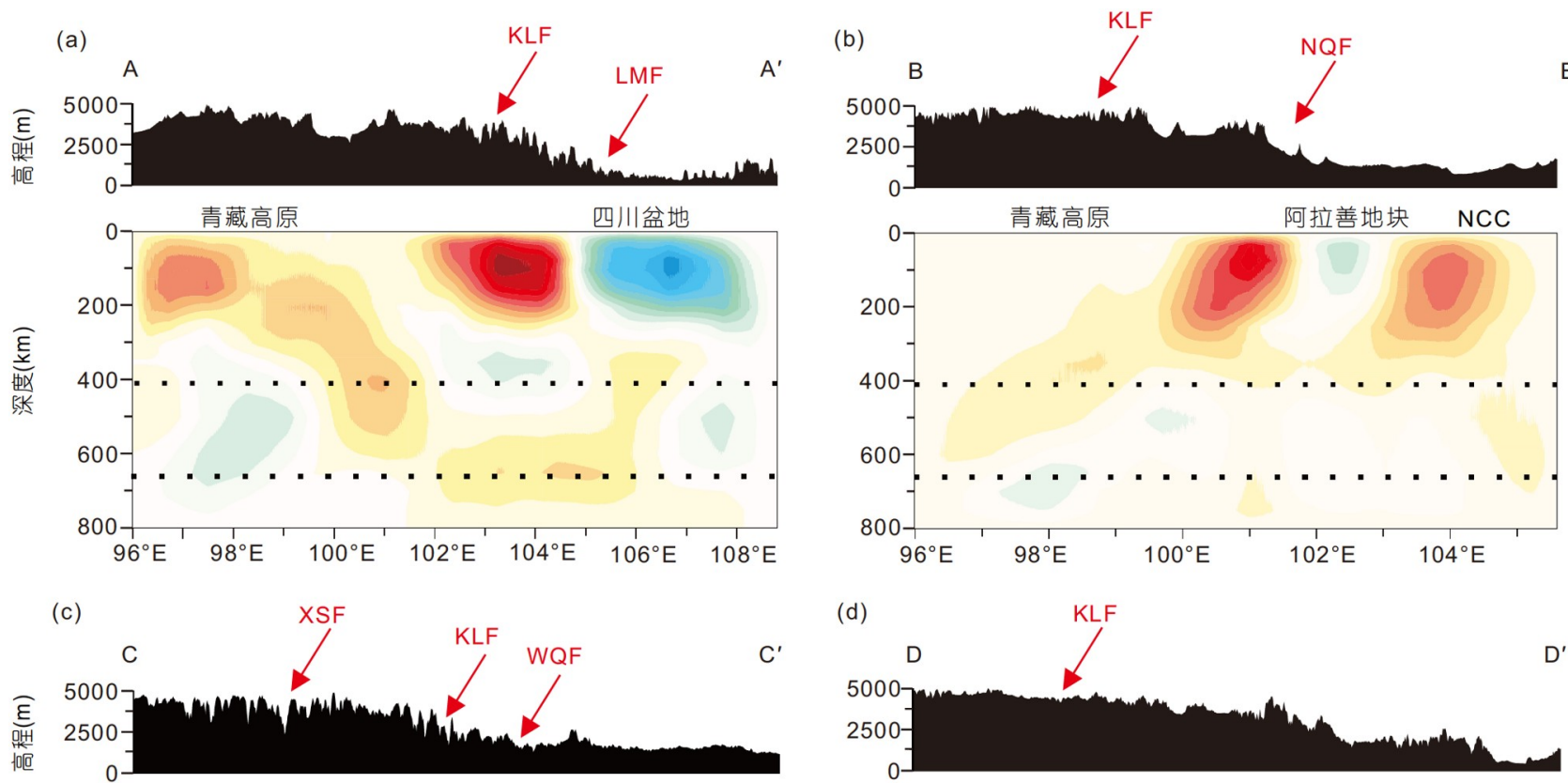

(d)
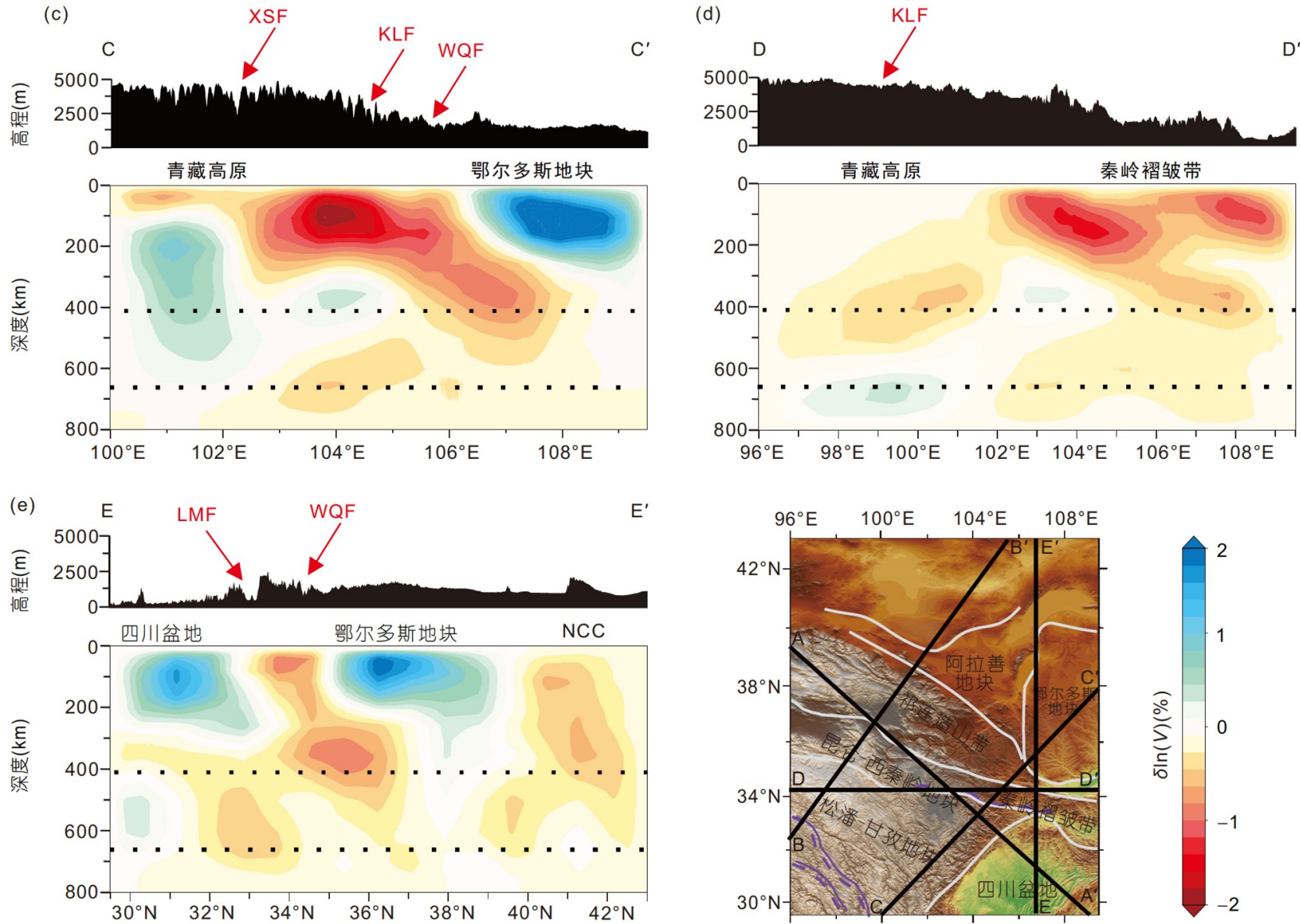

图 11 成像结果的垂直切片

(a) (e)也显示了对应剖面的地表高程. 黑色点线表示 $410 \mathrm{~km}$ 和 $660 \mathrm{~km}$ 不连续面, 剖面位置显示在右下角的插入图中, 相对速度扰动的比例尺显 示在图的右下角. KLF, 昆仑断裂; LMF, 龙门山断裂; NQF, 北祁连断裂; XSF, 鲜水河断裂; WQF, 西秦岭断裂

体和四川盆地下方岩石圈为负的径向各向异性，合成 模型中异常体径向各向异性扰动的强度为 $1.5 \%$. 测试 流程主要分为两步. 首先利用FMM在合成模型中计算
合成走时，并在合成走时中加入 $0.1 \mathrm{~s}$ 的高斯随机噪声. 然后采用与实际数据成像相同的参数，同时反演包含 $\mathrm{P}$ 波速度和径向各向异性模型信息的合成数据，并得 
到反演测试结果(图12和13). 图12中P波速度结构的恢 复性测试结果显示, 异常体的形态和扰动强度得到了 较好地恢复, 说明实际数据反演的 $\mathrm{P}$ 波速度主要特征 是可靠的. 虽然在阿拉善块体和鄂尔多斯块体北端出 现了低速异常假象，但低速异常的扰动强度明显低于 祁连造山带和松潘-甘孜地块东部下方的低速异常的 扰动强度. 虽然在昆仑断裂南部出现了高速异常假象, 但高速异常的规模要明显小于阿拉善块体、鄂尔多斯 块体和四川盆地下方的高速异常. 图13中径向各向异 性的恢复性测试反演结果与合成模型具有较好的一致 性. 虽然鄂尔多斯块体北部存在正径向各向异性假象, 但其强度要明显低于祁连造山带和松潘-甘孜地块东 部下方的正径向各向异性强度，虽然在祁连造山带北 部和松潘-甘孜块体存在负径向各向异性假象, 但其强 度要明显低于鄂尔多斯块体和四川盆地下方的负径向
各向异性. 恢复性测试结果表明本文所讨论的主要特 征可由本文的实际数据和反演方法所分辨.

\section{4 讨论}

\section{1 青藏高原东北缘下地壳通道流}

印度板块向欧亚板块的俯冲导致青藏高原地壳垂 向增厚，然而青藏高原壳内物质不是均匀增厚，Clark 和Royden(2000)发现青藏高原大多数区域地势变化较 缓，上地壳缩短现象仅发生在青藏高原边缘地形起伏 变化较大的区域，仅仅通过上地壳缩短增厚模型无法 解释整个青藏高原具有较厚地壳 $(70 \mathrm{~km}$, Zhang等, 2014)这种现象, 他们通过数值模拟发现青藏高原中下 地壳存在粘度系数较低的韧性物质，提出了中下地壳 流地球动力学模型, 认为青藏高原中下地壳存在东向
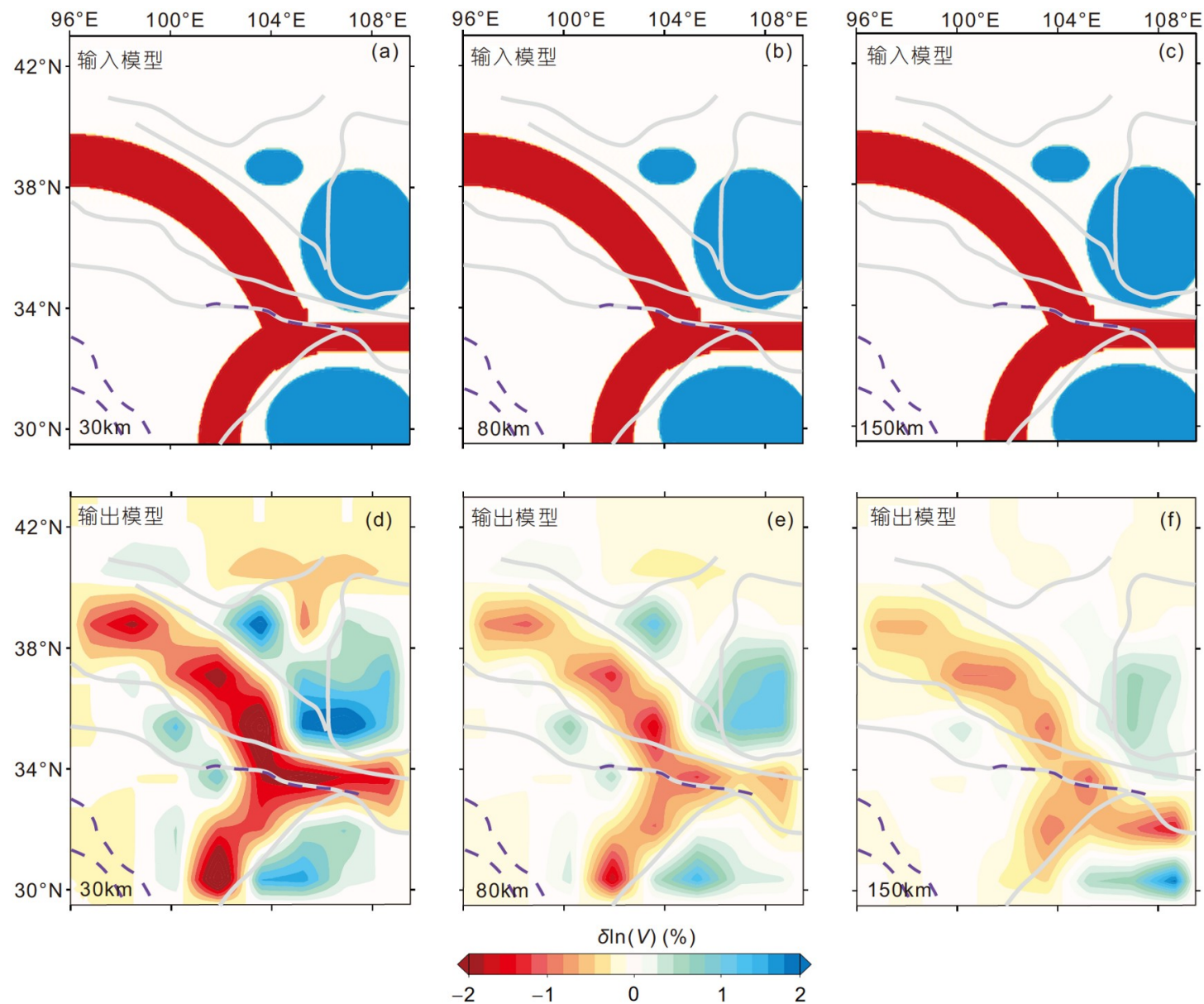

图 12 水平切片上的P波速度恢复性测试结果

水平切片对应的深度显示在子图的左下角, 其中(a) (c)代表输入模型, (d) (f)代表输出模型. 速度相对扰动的比例尺显示在图的底部 

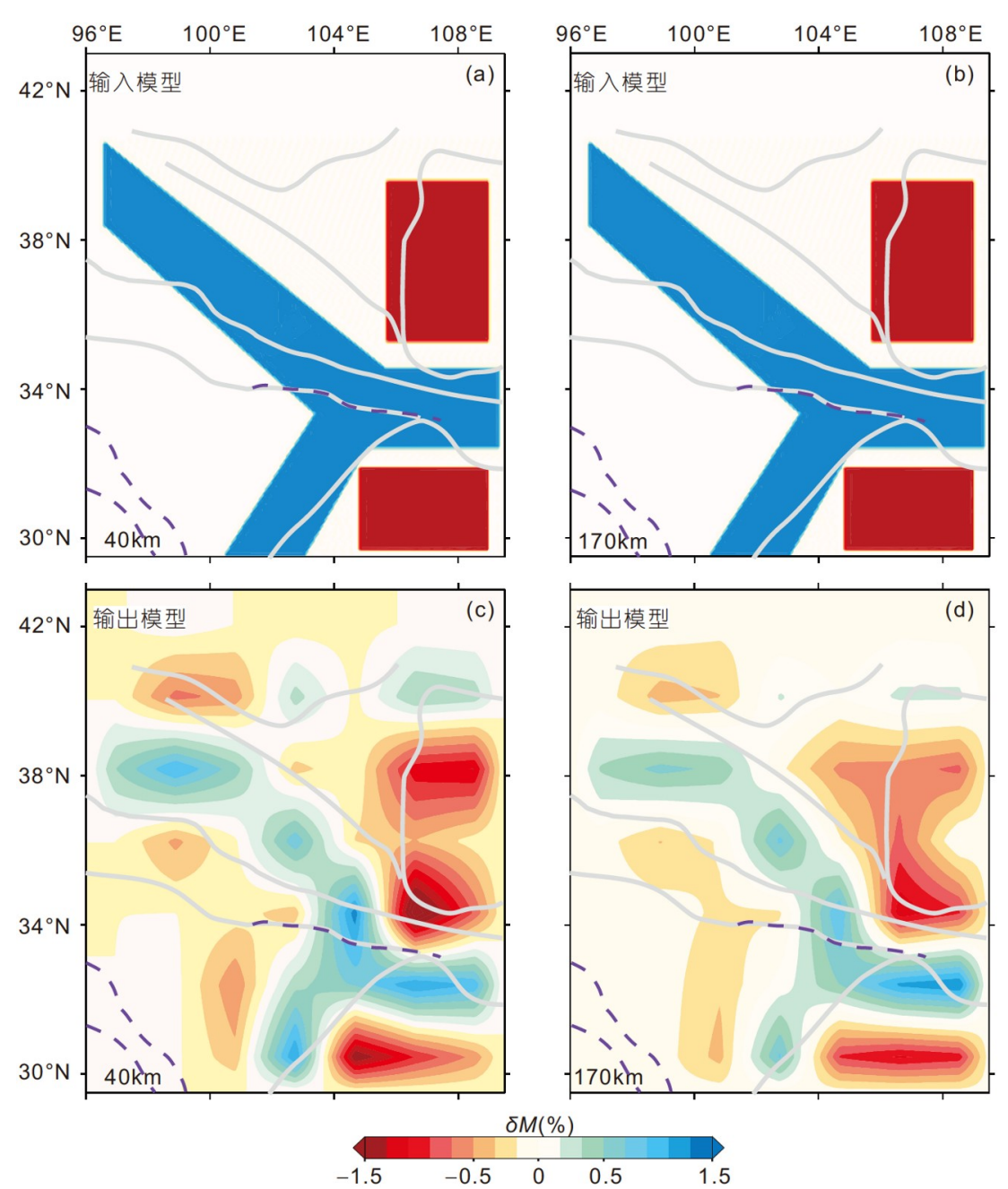

图 13 水平切片上的P波速度径向各向异性恢复性测试结果

水平切片对应的深度显示在子图的左下角, 其中(a) (b)代表输入模型, (c) (d)代表输出模型. 径向各向异性扰动幅度比例尺显示在图的底部

流动韧性流体, 当㓞性流体向东流动遇到稳定地块(如 四川盆地)的阻挡作用后流动方向发生改变, 在青藏高 原东缘分为东北和东南两支. 该中下地壳流模型已被 广泛应用于解释青藏高原及邻近地区的构造变形(Xu 等，2014; Hu和Wang，2018; Dong等，2019; Wu等， 2019). 径向各向异性研究显示青藏高原东北缘上地壳 表现出负径向各向异性，可能与上地壳水平方向上缩 短和垂直方向上增厚的变形有关，下地壳表现出正径 向各向异性，可能与水平向流动的下地壳流有关 (Huang等, 2010; Li等, 2016; 翟辰等, 2020). 本文P波 速度模型显示(图9a和 $9 b$, 图 $11 \mathrm{~d}$ 和 $11 \mathrm{e}$ )祁连造山带、松 潘-甘孜地块东北部和秦岭褶皱带西部下方 $30 \sim 80 \mathrm{~km}$ 表现为显著的低速异常, 并且Bao等(2013)通过面波层
析成像发现青藏高原东北缘地壳厚度为 $60 \mathrm{~km}$ ，因此 该区域下方下地壳表现为低速异常, 说明这些区域下 方下地壳物质具有较高的温度, 易发生变形和部分熔 融. Bao等(2013)通过面波层析成像发现祁连造山带和 松潘-甘孜地块东北部下地壳表现为低速异常, Bao等 (2015)同样观测到该区域存在低速异常，该低速异常 向下延伸至 $65 \mathrm{~km}$. Wang等(2014)通过远震P波层析成 像发现祁连造山带30 80 km深度处表现为明显的低速 异常. Hu和Wang(2018)的地震层析成像结果显示秦岭 禇皱带下方 $80 \mathrm{~km}$ 深度以上均表现为低速异常, 他们的 成像结果与本文的结果相一致. 然而付媛媛和肖卓 (2020)、Li等(2021)面波层析成像结果显示秦岭褶皱 带下地壳表现为高速异常, 与本文的P波层析成像结果 
不同.

$\mathrm{P}$ 波径向各向异性反演结果(图10a和 $10 \mathrm{~b}$ )显示祁 连造山带、松潘-甘孜地块东北部和秦岭褶皱带西部 下方 $40 \mathrm{~km}$ 深度处具有较强的正径向各向异性. Zhang 等(2014)通过面波频散反演得到祁连造山带、松潘-甘 孜地块东北部和秦岭褶皱带西部地壳厚度为 45 50km, 本文反演结果显示该区域下地壳 $(40 \mathrm{~km})$ 均 表现为明显的负 $\mathrm{P}$ 波速度异常和正径向各向异性, 很可 能暗示祁连造山带、松潘-甘孜地块东北部和秦岭褶 皱带西部下地壳存在水平流动的㓞性流体. Shen等 (2015)通过接收函数研究发现祁连造山带、松潘-甘孜 地块东北部和秦岭褶皱带西部下地壳存在较强的方位 各向异性； Li等(2021)通过地磁数据反演了青藏高原 东部的Moho面温度，发现祁连造山带Moho面温度较 高 $\left(\sim 1000^{\circ} \mathrm{C}\right)$, 他们认为祁连造山带下地壳物质发生了 部分熔融, 具有较高的流变性. 他们的结论与本文观点 一致.

\section{2 青藏高原东北缘岩石圈变形和地幔流}

根据前人研究，青藏高原下方岩石圈低速异常可 能来源于构造剪切应力引起的应变生热或地幔深部物 质上涌(Ceylan等，2012；Liang等，2012；Lei和Zhao， 2016). 本文径向各向异性结果显示，当深度大于 $400 \mathrm{~km}$ 时，祁连造山带、松潘-甘孜地块东北部和秦岭 褶皱带西部下方不存在明显的低速异常(图11)并且未 表现出明显的径向各向异性特征(图10)，说明该区域 不存在垂向流动的地幔流，所以这些区域下方岩石圈 低速异常很可能源于应力加热. $\mathrm{P}$ 波速度反演结果显 示祁连造山带、松潘-甘孜地块东北部和秦岭褶皱带 西部在150 250km深度处表现为明显的低速异常(图 9c和 $9 d), A n$ 和Shi(2006)通过反演青藏高原下方温度结 构得到祁连造山带、松潘-甘孜地块东北部和秦岭褶 皱带西部下方岩石圈厚度为120 160km，因此本文成 像结果显示该区域下方软流圈主要表现为明显的低速 异常，很可能表明这些区域下方软流圈具有较高的流 变性. 径向各向异性结果显示祁连造山带、松潘-甘孜 地块东北部和秦岭褶皱带西部上地幔顶部表现出明显 的正径向各向异性(图 $10 \mathrm{a}$ 和 $10 \mathrm{~b}$ ), 当深度增加时 $(>170 \mathrm{~km})$, 正径向各向异性逐渐消失，表明正的径向 各向异性主要分布在 $170 \mathrm{~km}$ 以上深度. 根据王琼等 (2013)研究，地壳介质各向异性对上地幔介质各向异
性的贡献很小，上地幔各向异性主要来源于岩石圈和 软流圈, 表明祁连造山带、松潘-甘孜地块东北部和秦 岭褶皱带西部下方上地幔明显的正径向各向异性主要 来源于岩石圈和软流圈顶部，正径向各向异性可能来 源于岩石圈水平向的形变或软流圈水平向流动，表明 该区域下方可能发生了水平向岩石圈变形和(或)软流 圈物质流动.

王琼等(2013)通过剪切波分裂研究发现祁连造山 带下方各向异性快波方向为NW-SE方向，近似平行于 全球地幔热点参考系下欧亚板块运动方向 $(\mathrm{NW})$ (Gripp和Gordon，2002)，符合软流圈流动模型(Silver, 1996)，表明该区域上地幔各向异性部分来源于软流圈 (王椿锯等，2006). 祁连造山带岩石圈厚度为 $160 \mathrm{~km}$ (An和Shi，2006)，本文径向各向异性反演结果表明祁 连造山带在 $170 \mathrm{~km}$ 深度处均具有明显的正径向各向异 性(图10b), 该区域软流圈具有明显的正径向各向异性, 表明祁连造山带下方软流圈存在水平向流体，支持祁 连造山带下方上地幔各向异性部分源于软流圈物质流 动的观点. 本文成像结果显示祁连造山带下方 $250 \mathrm{~km}$ 以上均表现出明显的低速异常(图9a 9c), 表明祁连造 山带下方岩石圈受到较强的应力加热作用而表现为热 的岩石圈(Li等, 2016; Zhang等, 2018), 综合前人研究 (王琼等, 2013), 本文认为祁连造山带下方存在岩石圈 变形和软流圈物质流动.

$\mathrm{P}$ 波速度反演结果显示松潘-甘孜地块东北部下方 存在明显的低速异常体(图9a 9c), 该低速异常体向下 延伸至 250km深度处(图11a和11c), 该低速异常也被 前人的地震成像所证实(Huang和Zhao，2006; Lei和 Zhao, 2016; Zhang等，2018; 董兴朋和滕吉文，2018; Li等，2021). 松潘-甘孜地块东北部岩石圈厚度为 130km(An和Shi，2006), 本文成像结果显示该区域岩 石圈波速表现为明显的低速异常，结合Zhang等(2018) 关于低速体的讨论，本文认为该区域岩石圈受到较强 的构造应力而具有较弱的力学性质. Ye等(2016)通过 剪切波分裂研究发现松潘-甘孜地块地壳各向异性快 波方向和上地幔快波方向相一致，他们认为松潘-甘孜 地块下方岩石圈变形是耦合的，岩石圈变形模式为垂 直连贯变形. 松潘-甘孜地块北部下方岩石圈厚度为 $\sim 130 \mathrm{~km}$ (An和Shi，2006), 张洪双等(2013)通过接收函 数和剪切波分裂研究发现该区域剪切波分裂延迟时间 变化较大 $(0.13 \sim 0.52 \mathrm{~s})$, 这种现象难以只通过岩石圈变 
形解释，因此他们认为该区域各向异性部分源于地幔 物质流动. 本文径向各向异性成像结果显示松潘-甘孜 地块东北部170km深度处表现为明显的正径向各向异 性(图10b), 表明松潘-甘孜地块东北部下方软流圈具有 正径向各向异性，这种正径向各向异性可能主要由松 潘-甘孜地块东北部下方软流圈物质水平流动引起, 结 合前人研究成果(张洪双等, 2013; Ye等, 2016), 本文认 为松潘-甘孜地块东北部上地幔各向异性来源主要为 岩石圈变形和软流圈流.

图11d和11e显示秦岭褶皱带西部下方存在明显的 低速异常体，该低速异常体向下延伸至 $250 \mathrm{~km}$ 深度 处，秦岭褶皱带西部岩石圈厚度为 $130 \mathrm{~km}$ (An 和Shi, 2006), 该区域下方岩石圈和软流圈均表现为明显的低 速异常，这种现象可能代表了岩石圈变形与软流圈流 动. Gao等(2019)通过剪切波分裂研究发现秦岭褶皱带 西部具有地壳与上地幔解耦的双层各向异性特征，其 中上地幔向异性层偏振方向为NWW-SEE向，与昆仑 断裂和海原断裂走向一致，他们认为秦岭褶皱带西部 下方可能存在岩石圈变形，本文成像结果中秦岭褶皱 带西部下方岩石圈表现为明显的低速异常(图 $11 \mathrm{~d}$ 和 11e)，表明该区域下方岩石圈易发生变形，支持该区域 下方岩石圈发生变形的观点. 另外，Hu和Wang(2018) 的地震层析成像结果显示秦岭褶皱带下方 100 200km 深度处存在低速异常, 他们认为该低速异常为青藏高 原软流圈物质向东部迁移的通道. Huang等(2008)通过 剪切波分裂分析发现秦岭褶皱带下方剪切波分裂时间 大于 $1.8 \mathrm{~s}$, 具有强的方位各向异性, 他们认为这种强的 各向异性是秦岭褶皱带下方软流圈物质流动造成的. Huang等(2008)、Hu和Wang(2018)的研究结果表明秦 岭褶皱带下方存在软流圈流，本文径向各向异性成像 结果显示秦岭褶皱带西部岩石圈底部方向(深度为 $170 \mathrm{~km}$ )表现为明显的正径向各向异性(图10b), 表明秦 岭褶皱带西部下方软流圈具有正径向各向异性，可能 代表了软流圈物质水平向流动. 因此，综合本文结果 与前人研究(Huang等, 2008; Gao等, 2019; Hu和Wang, 2018), 本文认为秦岭褶皱带西部下方存在岩石圈变形 与软流圈流.

\section{3 川滇块体下方的印度板块}

地震学和岩石学研究均证实印度板块俯冲至欧亚 板块下方(Coulon等, 1986; Arnaud等, 1992; Turner等,
1993, 1996; Ding等, 2003; Huang和Zhao, 2006), 但印度 板块的俯冲前缘存在争议(Owens和Zandt, 1997; Kosarev等, 1999; Lei和Zhao, 2016; Li等, 2021).

$\mathrm{P}$ 波速度扰动(图11c)显示在川滇块体北部上地幔 中存在显著的高速异常体，该高速异常从 $150 \mathrm{~km}$ 向下 延伸至 $\sim 500 \mathrm{~km}$ 深度处. 青藏高原东北缘岩石圈厚度为 $\sim 150 \mathrm{~km}$ ，其下方俯冲的印度板块应位于 $150 \mathrm{~km}$ 深度以 下, 川滇块体北部的高速异常所处位置较深 (150 500km), 并且高速异常体北缘(位于鲜水河断裂 下方) 接近班公-怒江缝合带, 所以该异常很可能是北 向俯冲的印度板块. Lei和Zhao(2016)通过远震P波层 析成像发现青藏高原东部下方地幔转换带存在近水平 的高速异常体, 他们认为该高速体为北向俯冲的印度 板块, 并认为板块俯冲前缘位于昆仑断裂下方地幔转 换带，与本文成像结果不一致(图9). 然而Wei等(2012) 通过区域地震P波层析成像发现青藏高原东部下方 100 300km存在近水平的高速异常体，该高速异常体 北缘接近班公-怒江缝合带. 最近面波层析成像研究结 果显示，印度板块在青藏高原东部俯冲前缘接近金沙 江缝合带(Li和Song, 2018), 然而Li和Song(2018)的结 果只能显示青藏高原东北缘浅部结构 $(<200 \mathrm{~km})$, 缺少 印度板块深部速度结构信息，不能显示印度板块深部 的结构. 经过上述讨论, 关于印度板块北缘位置, 通过 不同方法或数据得到的成像结果存在一定的差别, 所 以不能准确地确定青藏高原东北缘下方印度板块北缘 所在的位置. 尽管如此, 可以确定北向俯冲的印度板块 前缘至少已经到达班公-怒江缝合带下方, 因此本文认 为印度板块俯冲的前缘可能位于鲜水河断裂下方.

\section{5 结论}

本文通过基于程函方程的远震P波走时层析成像 得到了青藏高原东北缘 $\mathrm{P}$ 波速度和径向各向异性结构. 根据P波速度和径向各向异性的成像结果主要得到了 以下四方面结论:

(1) 鄂尔多斯地块和四川盆地下方均存在高速异 常体, 高速异常体向下延伸至 200km，表明其下方岩 石圈具有较强的力学强度. 鄂尔多斯地块和四川盆地 下方 40 和 $170 \mathrm{~km}$ 深度处均表现为明显的负径向各向异 性，其负径向各向异性可能来源于原始的“化石”径向 各向异性. 
（2） P波速度结构反演结果显示祁连造山带、松 潘-甘孜地块东北部和秦岭褶皱带西部下方 $30 \mathrm{~km}$ 表现 为显著的低速异常. P波径向各向异性反演结果显示祁 连造山带、松潘-甘孜地块东北部和秦岭褶皱带西部 下方 $40 \mathrm{~km}$ 深度处具有较强的正径向各向异性，表明这 些区域下地壳具有较高的流变性并存在水平物质 流动.

（3） P波速度结构反演结果显示祁连造山带、松 潘-甘孜地块东北部和秦岭褶皱带西部下方表现为显 著的低速异常，该低速异常向下延伸至 200km，表明 这些区域下方岩石圈具有较弱的力学性质. P波径向各 向异性反演结果显示祁连造山带、松潘-甘孜地块东 北部和秦岭褶皱带西部下方 $170 \mathrm{~km}$ 深度处具有较强的 正径向各向异性，表明这些区域下方具有弱的岩石圈， 并且存在软流圈物质水平流动.

(4) P波速度扰动显示在川滇块体北部上地幔中存 在显著的高速异常体, 其北缘接近鲜水河断裂, 本文认 为该高速异常为印度板块, 其俯冲的前缘可能接近鲜 水河断裂, 并未到达昆仑断裂.

致谢感谢编委和审稿专家对本文提出的宝贵修改意 见. 感谢中国地震局地球物理研究所“国家数字测震台网 数据备份中心”和中国地震局地球物理研究所地震科学 数据中心为本研究提供地震波形数据. 本文所有图件由 GMT绘制.

\section{参考文献}

常利军, 王椿镛, 丁志峰, 周民都, 杨建思, 徐智强, 姜旭东, 郑秀芬. 2008. 青藏高原东北缘上地幔各向异性研究. 地球物理学报, 51 : $431-438$

常利军, 丁志峰, 王椿镛. 2016. 南北构造带北段上地幔各向异性特 征. 地球物理学报, 59: 4035-4047

董兴朋, 滕吉文. 2018. 青藏高原东北缘远震P波走时层析成像研究. 地球物理学报, 61: 2066-2074

付媛媛，肖卓. 2020. 青藏高原东北缘及邻区Rayleigh和Love波背景 噪声层析成像. 地球物理学报, 63: 860-870

姜光政, 高楜, 饶松, 张林友, 唐晓音, 黄方, 赵平, 庞忠和, 何丽娟, 胡 圣标, 汪集旸. 2016. 中国大陆地区大地热流数据汇编(第四版). 地球物理学报, 59: 2892-2910

㫿辰, 胥烦, 杨文采, 汪晟, 刘晓宇. 2020. 青藏高原P波速度层析成像 与岩石圈结构. 地球物理学报, 63: 847-859

滕吉文, 杨顶辉, 田小波, 徐涛, 陈呰, 白志明, 梁晓峰, 张晰, 吴晶, 刘
有山. 2019. 青藏高原深部地球物理探测70年. 中国科学:地球科 学, 49: 1546-1564

王椿镛, 吴建平, 楼海, 常利军, 苏伟. 2006. 青藏高原东部壳幔速度 结构和地幔变形场的研究. 地学前缘, 13: 349-359

王椿镛, 杨文采, 吴建平, 丁志峰. 2015. 南北构造带岩石圈结构与地 震的研究. 地球物理学报, 58: 3867-3901

汪集旸, 黄少鹏. 1988. 中国大陆地区大地热流数据汇编. 地质科学, 2: 196-204

王琼, 高原, 石玉涛, 吴晶. 2013. 青藏高原东北缘上地幔地震各向异 性: 来自SKS, PKS和SKKS震相分裂的证据. 地球物理学报, 56 : 892-905

喜马拉雅地震科学台阵. 2011. 中国地震科学探测台阵波形数据 ——喜马拉雅计划. 中国地震局地球物理研究所, doi: 10.12001/ ChinArray.Data.Himalaya

张洪双, 滕吉文, 田小波, 张中杰, 高锐. 2013. 青藏高原东北缘岩石 圈厚度与上地幔各向异性. 地球物理学报, 56: 459-471

郑秀芬, 欧阳赂, 张东宁, 姚志祥, 梁建宏, 郑洁. 2009. “国家数字测 震台网数据备份中心”技术系统建设及其对汶川大地震研究的 数据支撑. 地球物理学报, 52: 1412-1417

中国地震科学台阵. 2006. 中国地震科学探测台阵波形数据. 中国地 震局, doi: 10.12001/ChinArray.Data

An M, Shi Y. 2006. Lithospheric thickness of the Chinese continent. Phys Earth Planet Inter, 159: 257-266

Almqvist B S G, Mainprice D. 2017. Seismic properties and anisotropy of the continental crust: Predictions based on mineral texture and rock microstructure. Rev Geophys, 55: 367-433

Arnaud N O, Vidal P, Tapponnier P, Matte P, Deng W M. 1992. The high $\mathrm{K}_{2} \mathrm{O}$ volcanism of northwestern Tibet: Geochemistry and tectonic implications. Earth Planet Sci Lett, 111: 351-367

Backus G E. 1962. Long-wave elastic anisotropy produced by horizontal layering. J Geophys Res, 67: 4427-4440

Backus G E. 1965. Possible forms of seismic anisotropy of the uppermost mantle under oceans. J Geophys Res, 70: 3429-3439

Bao X W, Song X D, Xu M J, Wang L S, Sun X X, Mi N, Yu D Y, Li H. 2013. Crust and upper mantle structure of the North China Craton and the NE Tibetan Plateau and its tectonic implications. Earth Planet Sci Lett, 369-370: 129-137

Bao X W, Song X D, Li J T. 2015. High-resolution lithospheric structure beneath Mainland China from ambient noise and earthquake surface-wave tomography. Earth Planet Sci Lett, 417: 132141

Ceylan S, Ni J, Chen J Y, Zhang Q, Tilmann F, Sandvol E. 2012. Fragmented Indian plate and vertically coherent deformation beneath eastern Tibet. J Geophys Res, 117: B11303

Chang L J, Ding Z F, Wang C Y, Flesch L. 2017. Vertical coherence of deformation in lithosphere in the NE margin of the Tibetan Plateau 
using GPS and shear-wave splitting data. Tectonophysics, 699: 93101

Chen M, Niu F L, Liu Q Y, Tromp J, Zheng X F. 2015. Multiparameter adjoint tomography of the crust and upper mantle beneath East Asia: 1. Model construction and comparisons. J Geophys Res-Solid Earth, 120: $1762-1786$

Clark M K, Royden L H. 2000. Topographic ooze: Building the eastern margin of Tibet by lower crustal flow. Geology, 28: 703-706

Coulon C, Maluski H, Bollinger C, Wang S. 1986. Mesozoic and cenozoic volcanic rocks from central and southern Tibet: ${ }^{39} \mathrm{Ar}-{ }^{40} \mathrm{Ar}$ dating, petrological characteristics and geodynamical significance. Earth Planet Sci Lett, 79: 281-302

Crampin S, Peacock S. 2005. A review of shear-wave splitting in the compliant crack-critical anisotropic Earth. Wave Motion, 41: 59-77

Crotwell H P, Owens T J, Ritsema J. 1999. The taup toolkit: Flexible seismic travel-time and ray-path utilities. Seismol Res Lett, 70: 154160

Deng Y F, Shen W S, Xu T, Ritzwoller M. 2015. Crustal layering in northeastern Tibet: A case study based on joint inversion of receiver functions and surface wave dispersion. Geophys J Int, 203: 692-706

Ding L, Kapp P, Zhong D L, Deng W M. 2003. Cenozoic volcanism in tibet: Evidence for a transition from oceanic to continental subduction. J Petrol, 44: 1833-1865

Dong X P, Yang D H, Niu F L. 2019. Passive adjoint tomography of the crustal and upper mantle beneath Eastern Tibet with a W2-norm misfit function. Geophys Res Lett, 46: 12986-12995

Eberhart-Phillips D, Henderson C. 2004. Including anisotropy in 3-D velocity inversion and application to Marlborough, New Zealand. Geophys J Int, 156: 237-254

England P, McKenzie D. 1982. A thin viscous sheet model for continental deformation. Geophys J Int, 70: 295-321

Gao Y, Chen L, Wang X, Ai Y. 2019. Complex lithospheric deformation in eastern and Northeastern Tibet from shear wave splitting observations and its geodynamic implications. J Geophys Res-Solid Earth, 124: 10331-10346

Gripp A E, Gordon R G. 2002. Young tracks of hotspots and current plate velocities. Geophys J Int, 150: 321-361

Hacker B R, Ritzwoller M H, Xie J. 2014. Partially melted, micabearing crust in Central Tibet. Tectonics, 33: 1408-1424

Harmon N, Rychert C A. 2015. Seismic imaging of deep crustal melt sills beneath Costa Rica suggests a method for the formation of the Archean continental crust. Earth Planet Sci Lett, 430: 140-148

Hearn T M. 1996. Anisotropic Pn tomography in the western United States. J Geophys Res, 101: 8403-8414

Hestenes M R, Stiefel E. 1952. Methods of conjugate gradients for solving linear systems. J Res Natl Bur Stan, 49: 409-436
Hu Y P, Wang Z. 2018. Plate interactions, crustal deformation and magmatism along the eastern margins of the Tibetan Plateau. Tectonophysics, 740-741: 10-26

Huang J L, Zhao D P. 2006. High-resolution mantle tomography of China and surrounding regions. J Geophys Res, 111: B09305

Huang Z C, Xu M J, Wang L S, Mi N. 2008. Shear wave splitting in the southern margin of the Ordos block, North China. Geophys Res Lett, 35: L19301

Huang H, Li Y, Yao H B, Hilst R. 2010. Radial anisotropy in the crust of SE Tibet and SW China from ambient noise interferometry. Geophys Res Lett, 37: L21310

Jaxybulatov K, Shapiro N M, Koulakov I, Mordret A, Landès M, SensSchönfelder C. 2014. A large magmatic sill complex beneath the Toba caldera. Science, 346: 617-619

Jiang C X, Schmandt B, Farrell J, Lin F C, Ward K M. 2018. Seismically anisotropic magma reservoirs underlying silicic calderas. Geology, 46: 727-730

Kennett B L N, Engdahl E R, Buland R. 1995. Constraints on seismic velocities in the Earth from traveltimes. Geophys J Int, 122: 108124

Kosarev G, Kind R, Sobolev S V, Yuan X, Hanka W, Oreshin S. 1999. Seismic evidence for a detached Indian lithospheric mantle beneath Tibet. Science, 283: 1306-1309

Karato S I, Jung H, Katayama I, Skemer P. 2008. Geodynamic significance of seismic anisotropy of the upper mantle: New insights from laboratory studies. Annu Rev Earth Planet Sci, 36: 59-95

Laske G, Masters G, Ma Z, Pasyanos M. 2013. Update on CRUST1.0-A 1-degree global model of Earth's crust. Geophys Res Abstracts. 15: EGU2013-2658

Leary P C, Crampin S, McEvilly T V. 1990. Seismic fracture anisotropy in the Earth's crust: An overview. J Geophys Res, 95: 11105-11114

Lei J S, Zhao D P. 2016. Teleseismic P-wave tomography and mantle dynamics beneath Eastern Tibet. Geochem Geophys Geosyst, 17: 1861-1884

Li L, Li A B, Murphy M A, Fu Y V. 2016. Radial anisotropy beneath northeast Tibet, implications for lithosphere deformation at a restraining bend in the Kunlun fault and its vicinity. Geochem Geophys Geosyst, 17: 3674-3690

Li J T, Song X D. 2018. Tearing of Indian mantle lithosphere from high-resolution seismic images and its implications for lithosphere coupling in southern Tibet. Proc Natl Acad Sci USA, 115: 82968300

Li L, Zhang X Z, Liao J, Liang Y L, Dong S X. 2021. Geophysical constraints on the nature of lithosphere in central and eastern Tibetan Plateau. Tectonophysics, 804: 228722

Liang X F, Sandvol E, Chen Y J S, Hearn T M, Ni J, Klemperer S L, 
Shen Y, Tilmann F. 2012. A complex Tibetan upper mantle: A fragmented Indian slab and no south-verging subduction of Eurasian lithosphere. Earth Planet Sci Lett, 333-334: 101-111

Liu Q Y, van der Hilst R D, Li Y, Yao H J, Chen J H, Guo B, Qi S H, Wang J, Huang H, Li S C. 2014. Eastward expansion of the Tibetan Plateau by crustal flow and strain partitioning across faults. Nat Geosci, 7: 361-365

Liu S L, Suardi I, Yang D H, Wei S J, Tong P. 2018. Teleseismic traveltime tomography of northern sumatra. Geophys Res Lett, 45: 13231-13239

Liu S L, Suardi I, Zheng M, Yang D H, Huang X Y, Tong P. 2019. Slab morphology beneath Northern Sumatra revealed by regional and teleseismic traveltime tomography. J Geophys Res-Solid Earth, 124: 10544-10564

Liu S L, Suardi I, Xu X W, Yang S X, Tong P. 2021. The geometry of the subducted slab beneath Sumatra revealed by regional and teleseismic traveltime tomography. J Geophys Res-Solid Earth, 126: e20169

Liu Y S, Tong P. 2021. Eikonal equation-based P-wave seismic azimuthal anisotropy tomography of the crustal structure beneath northern California. Geophys J Int, 226: 287-301

Lynner C, Beck S L, Zandt G, Porritt R W, Lin F C, Eilon Z C. 2018 Midcrustal deformation in the Central Andes constrained by radial anisotropy. J Geophys Res-Solid Earth, 123: 4798-4813

Matharu G, Bostock M G, Christensen N I, Tromp J. 2014. Crustal anisotropy in a subduction zone forearc: Northern Cascadia. J Geophys Res-Solid Earth, 119: 7058-7078

Molnar P, Tapponnier P. 1975. Cenozoic Tectonics of Asia: Effects of a Continental Collision: Features of recent continental tectonics in Asia can be interpreted as results of the India-Eurasia collision. Science, 189: 419-426

Owens T J, Zandt G. 1997. Implications of crustal property variations for models of Tibetan Plateau evolution. Nature, 387: 37-43

Raitt R W, Shor G G J, Francis T J G, Morris G B. 1969. Anisotropy of the Pacific upper mantle. J Geophys Res, 74: 3095-3109

Rawlinson N, Sambridge M. 2005. The fast marching method: An effective tool for tomographic imaging and tracking multiple phases in complex layered media. Explor Geophys, 36: 341-350

Rawlinson N, Reading A M, Kennett B L N. 2006. Lithospheric structure of Tasmania from a novel form of teleseismic tomography. J Geophys Res, 111: B02301

Romanowicz B, Wenk H R. 2017. Anisotropy in the deep Earth. Phys Earth Planet Inter, 269: 58-90

Sethian J A, Popovici A M. 1999. 3-D traveltime computation using the fast marching method. Geophysics, 64: 516-523

Shearer P M. 1999. Introduction to Seismology. Cambridge: Cambridge
University Press. 361-365

Sharma J, Kumar M R, Roy K S, Pal S K, Roy P N S. 2021. Lowvelocity zones and negative radial anisotropy beneath the plume perturbed Northwestern Deccan Volcanic Province. J Geophys ResSolid Earth, 126: e20295

Shen X Z, Yuan X H, Ren J S. 2015. Anisotropic low-velocity lower crust beneath the northeastern margin of Tibetan Plateau: Evidence for crustal channel flow. Geochem Geophys Geosyst, 16: 42234236

Silver P G. 1996. Seismic anisotropy beneath the continents: Probing the depths of geology. Annu Rev Earth Planet Sci, 24: 385-432

Tapponnier P, Xu Z Q, Roger F, Meyer B, Arnaud N, Wittlinger G, Yang J S. 2001. Oblique stepwise rise and growth of the Tibet Plateau. Science, 294: 1671-1677

Tatham D J, Lloyd G E, Butler R W H, Casey M. 2008. Amphibole and lower crustal seismic properties. Earth Planet Sci Lett, 267: 118-128

Taylor M, Yin A. 2009. Active structures of the Himalayan-Tibetan orogen and their relationships to earthquake distribution, contemporary strain field, and Cenozoic volcanism. Geosphere, 5: 199-214

Tong P, Zhao D, Yang D, Yang X, Chen J, Liu Q. 2014. Wave-equationbased travel-time seismic tomography_Part 1: Method. Solid Earth, 5: 1151-1168

Turner S, Arnaud N, Liu J, Rogers N, Hawkesworth C, Harris N, Kelley S, Van Calsteren P, Deng W. 1996. Post-collision, Shoshonitic volcanism on the Tibetan Plateau: Implications for convective thinning of the lithosphere and the source of Ocean Island basalts. J Petrol, 37: 45-71

Turner S, Hawkesworth C, Liu J, Rogers N, Kelley S, van Calsteren P. 1993. Timing of Tibetan uplift constrained by analysis of volcanic rocks. Nature, 364 : 50-54

Vandecar J C, Crosson R S. 1990. Determination of teleseismic relative phase arrival times using multi-channel cross-correlation and least squares. Bull Seismol Soc Am, 80: 150-169

Wang C Y, Han W B, Wu J P, Lou H, Chan W W. 2007. Crustal structure beneath the eastern margin of the Tibetan Plateau and its tectonic implications. J Geophys Res, 112: B07307

Wang J, Zhao D P. 2013. P-wave tomography for 3-D radial and azimuthal anisotropy of Tohoku and Kyushu subduction zones. Geophys J Int, 193: 1166-1181

Wang J, Wu H H, Zhao D P. 2014. P wave radial anisotropy tomography of the upper mantle beneath the North China Craton. Geochem Geophys Geosyst, 15: 2195-2210

Wang X, Zhang J F, Jiang W L, Wang D H. 2019. Gravity field and deep seismogenic environment in the Longmen Shan and adjacent regions, Eastern Tibetan Plateau. J Asian Earth Sci, 176: 79-87

Wei W, Xu J D, Zhao D P, Shi Y L. 2012. East Asia mantle 
tomography: New insight into plate subduction and intraplate volcanism. J Asian Earth Sci, 60: 88-103

Wu C L, Xu T, Badal J, Wu Z B, Teng J W. 2015. Seismic anisotropy across the Kunlun fault and their implications for northward transforming lithospheric deformation in northeastern Tibet. Tectonophysics, 659: 91-101

Wu C L, Tian X B, Xu T, Liang X F, Chen Y, Taylor M, Badal J, Bai Z M, Duan Y H, Yu G P, Teng J W. 2019. Deformation of crust and upper mantle in central Tibet caused by the northward subduction and slab tearing of the Indian lithosphere: New evidence based on shear wave splitting measurements. Earth Planet Sci Lett, 514: 7583

Wu Z B, Xu T, Liang C, Wu C L, Liu Z Q. 2018. Crustal shear wave velocity structure in the northeastern Tibet based on the Neighbourhood algorithm inversion of receiver functions. Geophys J Int, 212: 1920-1931

Xu T, Wu Z, Zhang Z, Tian X B, Deng Y F, Wu C L. 2014. Crustal structure across the Kunlun fault from passive source seismic profiling in East Tibet. Tectonophysics, 627: 98-107

Ye Z, Li Q S, Gao R, Zhang H S, Shen X Z, Liu X Z, Chen G. 2016. Anisotropic regime across Northeastern Tibet and its geodynamic implications. Tectonophysics, 671: 1-8
Zhang J S, Gao R, Zeng L S, Li Q S, Guan Y, He R Z, Wang H Y, Lu Z W. 2010. Relationship between characteristics of gravity and magnetic anomalies and the earthquakes in the Longmenshan range and adjacent areas. Tectonophysics, 491: 218-229

Zhang F X, Wu Q J, Li Y H, Zhang R Q, Sun L, Pan J T, Ding Z F. 2018. Seismic tomography of eastern Tibet: Implications for the Tibetan Plateau growth. Tectonics, 37: 2833-2847

Zhang S Q, Karato S I. 1995. Lattice preferred orientation of olivine aggregates deformed in simple shear. Nature, 375: 774-777

Zhang X M, Teng J W, Sun R M, Romanelli F, Zhang Z J, Panza G. 2014. Structural model of the lithosphere-asthenosphere system beneath the Qinghai-Tibet Plateau and its adjacent areas. Tectonophysics, 634: 208-226

Zhao B, Huang Y, Zhang C, Wang W, Tan K, Du R. 2015. Crustal deformation on the Chinese mainland during 1998-2014 based on GPS data. Geodesy Geodyn, 6: 7-15

Zhao D P, Hua Y Y. 2021. Anisotropic tomography of the Cascadia subduction zone. Phys Earth Planet Inter, 318: 106767

Zhao D P, Yu S, Liu X. 2016. Seismic anisotropy tomography: New insight into subduction dynamics. Gondwana Res, 33: 24-43

Zheng Y F, Wu F Y. 2018. The timing of continental collision between India and Asia. Sci Bull, 63: 1649-1654

(责任编委: 陈凌) 